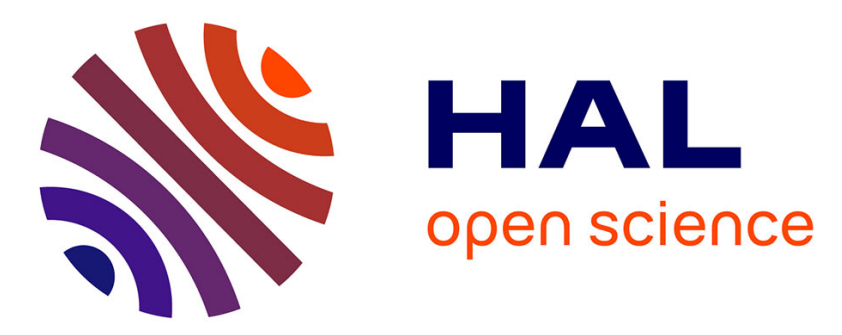

\title{
Assessment of hybrid RANS-LES formulations for flow simulation around the Ahmed body
}

\author{
Emmanuel Guilmineau, G.B. Deng, Alban Leroyer, P. Queutey, Michel
}

Visonneau, J. Wackers

\section{- To cite this version:}

Emmanuel Guilmineau, G.B. Deng, Alban Leroyer, P. Queutey, Michel Visonneau, et al.. Assessment of hybrid RANS-LES formulations for flow simulation around the Ahmed body. Computers and Fluids, 2018, 176, pp.302-319. 10.1016/j.compfluid.2017.01.005 . hal-02391167

\section{HAL Id: hal-02391167 \\ https://hal.science/hal-02391167}

Submitted on 22 Apr 2021

HAL is a multi-disciplinary open access archive for the deposit and dissemination of scientific research documents, whether they are published or not. The documents may come from teaching and research institutions in France or abroad, or from public or private research centers.
L'archive ouverte pluridisciplinaire HAL, est destinée au dépôt et à la diffusion de documents scientifiques de niveau recherche, publiés ou non, émanant des établissements d'enseignement et de recherche français ou étrangers, des laboratoires publics ou privés.

\section{(c)(1)}

Distributed under a Creative Commons Attribution| 4.0 International License 


\title{
Assessment of hybrid RANS-LES formulations for flow simulation around the Ahmed body
}

\author{
E. Guilmineau ${ }^{1}$, G.B. Deng, A. Leroyer, P. Queutey, M. Visonneau and J. \\ Wackers
}

LHEEA, CNRS UMR 6598, Ecole Centrale de Nantes, 1 rue de la Noë, BP 92101, 44321 Nantes Cedex 3, France

\begin{abstract}
This paper presents an investigation of RANS and DES models for the Ahmed body with $25^{\circ}$ and $35^{\circ}$ slant angles. The Reynolds number, based on the height of the model and the upstream velocity, is $7.68 \times 10^{5}$. Two RANS ( Reynolds Averaged Navier-Stokes) models are used: the $k-\omega$ SST of Menter and the EARSM (Explicit Algebraic Stress Model), based on the $k-\omega$ model. Two hybrid RANS-LES (Large Eddy Simulation) models are used: a DES (Detached Eddy Simulation) and an IDDES (Improved Delay Detached Eddy Simulation). These hybrid models are also based on the $k-\omega$ model. The flow for the slant angle $35^{\circ}$ is well predicted by all turbulence models with a slight advantage for the IDDES model. For the flow with the slant angle $25^{\circ}$, only the IDDES hybrid RANS-LES model predicts the recirculation bubble on the slant. It is concluded that the IDDES model is the only turbulence model that gives good agreements with the experimental data.
\end{abstract}

Keywords: Turbulence models, DES models, IDDES, RANS, Ahmed body, ISIS-CFD

\section{Introduction}

The numerical simulation of complex external flows is an important component of automotive design. For a typical configuration, a separated wake flow

\footnotetext{
${ }^{1}$ Corresponding author: Emmanuel.Guilmineau@ec-nantes.fr
} 
exists behind the car body, which contributes to the drag and thus influences

5 the fuel efficiency of the vehicle. Wind tunnel testing is still widely used but the need for reliable numerical tools is growing due to the relatively low cost associated with the numerical simulations. One of the major challenges in automotive industry, and in industrial applications in general, is the need of computational fluid dynamics (CFD) tools that simulate robustly and accurately the flow physics. External flows for high Reynolds number are characterized by highly turbulent and three-dimensional separation and reattachment phenomena. The ability of a CFD simulation to capture correctly these flow features is strongly linked to the quality of the turbulence model.

A direct numerical simulation (DNS) is not possible because, for engineering 15 applications, the Reynolds number is too high so in order to resolve the Kolmogorov scale, the required mesh size is too large. Therefore, this method is limited to low Reynolds numbers, and either Reynolds Averaged Navier-Sokes (RANS) or Large Eddy Simulation (LES) solutions are preferred. The choice between RANS or LES methods is dependent on the available computer re20 sources and the level of physical accuracy required. Computations based on RANS are commonly used in industry. Although they are very successful in predicting many parts of the flow around a vehicle, they are unable to predict the unsteadiness in the wake regions. The resulting failure in predicting the base pressure is the major reason for the large discrepancy in drag prediction

25 between the experiments and numerical simulations. In an attempt to improve the predictive capabilities of turbulence models in highly separated regions, Spalart et al. [1] proposed a hybrid approach which combines features of classical RANS formulations with elements of LES method. This concept has been termed Detached Eddy Simulation (DES) and is based on the idea of covering the boundary layer by a RANS model and switching the model to a LES mode in detached regions. Compared with classical LES methods, DES save orders of magnitude of computing power for high Reynolds number flows due to the moderate costs of the RANS model in the boundary layer region, but still offers some of the advantages of a LES method in the separated regions. Another 
approach based on the Lattice Boltzmann method (LBM) can be used which have been applied successfully to unsteady aerodynamics problem in aerospace space [2]. For the simulation of the flow around a generic SUV model, the results obtained with LBM or DES approaches have a high level of similarity [3].

The assessment of hybrid RANS-LES formulations for automotive applica40 tion is discussed in this paper. The car model selected is the Ahmed model [4]. This model has been chosen due to the availability of the experimental results. While this geometry is a much simpler a realistic car, many of the flow features can be found such as the large 3D separation region behind the model and the roll-up of vortices at the rear corners, called C-pillar vortices. The angle of the 45 rear slanted surface influences the structure of the wake and the reattachment point. In the literature, two slant angles are mostly investigated, numerically and experimentally: $25^{\circ}$ and $35^{\circ}$.

For the $35^{\circ}$ slant angle, the majority of studies $[5,6,7]$ use a RANS model. At this slant angle, a separation occurs over the entire rear slanted surface and most of RANS simulations capture correctly the flow and give a good agreement with the experimental data. A few numerical simulations with a DES approach $[8,9,7]$ have been published for this slant angle. The $25^{\circ}$ slant angle is the most extensively studied because this slant angle is a challenge for the numerical simulation. Indeed, a partial reattachment occurs on the rear slant. The 55 majority of RANS models $[10,11,5,6,12,13]$ fail to predict the flow correctly. Generally, they either predict no separation at all, or they are unable to predict the correct size of the recirculation region. A Lattice-Boltzmann approach [14] has provided more satisfactory results, but no turbulence profiles have been presented. A large number of LES studies have been performed for this slant ${ }_{60}$ angle $[15,16,17,18]$. Some studies are more successful than others. Krajnović and Davidson [16] predict the correct flow topology but with a lower Reynolds number because a sufficient spatial resolution in the Y-direction on the top and the roof, and in the Z-direction on the lateral sides could not be obtained for the experimental Reynolds number with the computer resources at that time.

${ }_{65}$ Serre et al. [18] indicate that the hybrid RANS-LES methods represent an at- 
tractive alternative with a specific focus on the mesh generation with regards to the RANS-LES interface. A number of DES studies [19, 8, 18, 13, 7] have been performed which have been shown that the use of a hybrid RANS-LES model offers an advantage over RANS models.

A new hybrid model, Improved Delayed Detached-Eddy Simulation (IDDES), proposed by Shur et al. [20], combines Delayed Detached-Eddy Simulation (DDES) and wall modelling in LES (WMLES) capabilities. This model is shown to resolve the issue of mismatch between the modelled log layer and the resolved log layer, which has been identified as a typical deficiency of DES. In general, the IDDES tangibly surpasses DES in the mixed flow with both attached and separated regions.

The objective of this paper is to evaluate the capabilities of the IDDES model for the simulation of automotive flows, and more particularly for the Ahmed body. The present paper is organized as follows. The test-case is presented in Section 2. Section 3 briefly describes the numerics and outlines the turbulence models used. The numerical set-up is presented in Section 4 including information about the computational domain and the meshes. In Section 5 the results for two slant angles are presented, using both RANS and hybrid RANS-LES methods. Finally, Section 6 provides the main conclusions of this 85 work.

\section{Generic ground vehicle body}

The Ahmed model [4] used for the numerical simulations is shown in Figure 1. It is a generic car geometry comprising a flat front with rounded corners and a sharp slanted rear upper surface. The slant angle is adjustable and is the

90 main variable model-parameter in the experimental investigations of Ahmed et al [4]. Most of drag of the body is due to the pressure drag which is generated at the rear end. The structure of the wake is very complex with a separation zone and counter-rotating vortices generated at the slant side edges. The strength of the separation is determined by the slant angle. The maximum drag is found for 
the critical slant angle of $30^{\circ}$. Above this angle, the adverse pressure gradient between the slant and the roof is so strong that the flow fully detaches over the slant. Below this angle, the flow still separates but the pressure difference between the slant region and the side walls is still strong enough to generate substantial streamwise vortices at the lateral slant edges. These induce a downward motion over the slant, mainly in the downstream part. As a consequence, the flow separating in the upstream end of the slant can reattach further downstream, which is observed in the experiments for the slant angle of $25^{\circ}$. The critical change in drag is due to the transition in the wake structure. Kohri et al. [21] showed that the transitional characteristics of the wake structure is dominated by the combination of the slant angle and aspect ratio. Lienhart and Becker [22] performed further experiments with the same body for the two representative slant angles $\varphi=25^{\circ}$ and $\varphi=35^{\circ}$. This study provides some well-defined LDA measurements of the mean velocity and turbulence statistics.

The length of the model is $L=1044 \mathrm{~mm}$, the width is $W=369 \mathrm{~mm}$, the height is $H=288 \mathrm{~mm}$. The ground clearance is $\mathrm{G}=50 \mathrm{~mm}$, and the diameter of the four feet, which are used to secure the model to the floor of the wind tunnel, is $\phi=30 \mathrm{~mm}$. The reference axis $(\mathrm{X}, \mathrm{Y}, \mathrm{Z})$ is linked to the model. The origin of these axis is related to the point $\mathrm{O}$ located on the floor of the wind tunnel at the base of the model and in the symmetry plane of the model, see Figure 1. The Reynolds number, $R e_{H}=7.68 \times 10^{5}$, is based on the height of the model and the incoming velocity, $U_{\infty}=40 \mathrm{~m} / \mathrm{s}$. This Reynolds number is the same as the one used in the experiments [22] which were conducted in a $3 / 4$ open test section with a blockage ratio of $4 \%$. The averaged turbulent intensity of the wind tunnel in the experiments of Lienhart and Becker [22] is less than $0.25 \%$

For the Ahmed body wake, the estimations length scales for the Kolmogorov scale is $\eta \simeq 1.2 \mathrm{Re}^{-0.75}$, and for the Taylor scale,$\lambda_{T} \simeq 5.5 \mathrm{Re}^{0.5}$. These estimations are proposed by Howard and Pourquie [23]. The length scale $l_{0}$ of the largest anisotropic structures containing energy may be estimated by $l_{0} \sim$ ${ }_{125} \eta \mathrm{Re}^{3 / 4}$. Then, the inertial range lies from $l_{E I} \sim l_{0} / 6$, between the anisotropic 


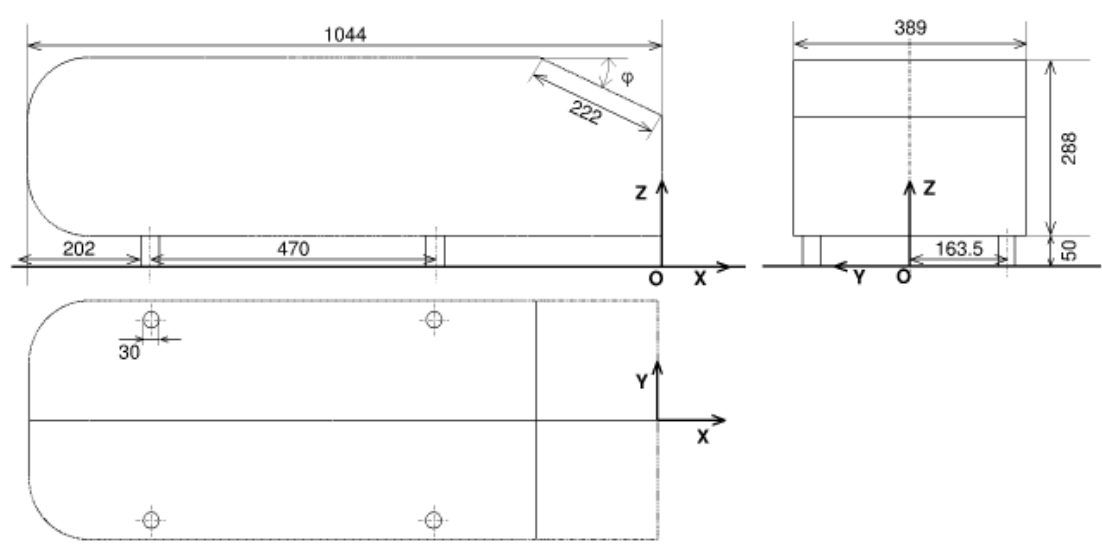

Figure 1: Side, rear and top view of the Ahmed body. Distances are in mm.

large eddies and the anisotropic small eddies, to $l_{D I} \sim 60 \eta$, between the inertial and dissipative range [17]. The viscous boundary sublayer at the end of the vehicle is $\eta_{n w} \sim 6.71 \mathrm{Re}^{-0.9}$, which equals 1 in wall units. All these lengths are given in Table 1.

Table 1: Characteristic length scales scales evaluated for the Ahmed body flow at $\mathrm{Re}=768$ 000

\begin{tabular}{ccccccc}
\hline & $l_{0}$ & $l_{E I}$ & $\lambda_{T}$ & $l_{D I}$ & $\eta$ & $\eta_{n w}$ \\
\hline Dimensionless & 1.2 & 0.02 & 0.0063 & 0.0028 & $4.63 \times 10^{-5}$ & $3.4 \times 10^{-5}$ \\
In mm & 345.6 & 57.6 & 1.807 & 0.799 & 0.013 & 0.0098 \\
\hline
\end{tabular}

In this study, the two slant angles investigated are the same as those used by Lienhart and Becker. [22].

\section{Numerical method}

\subsection{Flow solver}

The ISIS-CFD flow solver, developed by the Ecole Centrale de Nantes and

CNRS, uses an incompressible unsteady Reynolds-averaged Navier-Stokes (URANS) 
method. The solver is based on a finite volume method to build the spatial discretization of the transport equations. The unstructured discretization is facebased, which means that cells with an arbitrary number of arbitrarily shaped faces are accepted. A second order backward difference scheme is used to discretize time. The solver can simulate both steady and unsteady flows. In the case of turbulent flows, additional transport equations for the variables in the turbulence model are added.

The solver features sophisticated turbulence models: apart from the classical two-equation $\mathrm{k}-\varepsilon$ and $k-\omega$ models, the anisotropic two-equation Explicit Algebraic Reynolds Stress Model (EARSM), as well as Reynolds Stress Transport Models, are available, see Duvigneau et al. [24] and Deng and Visonneau [25]. All these are RANS models. A Detached Eddy Simulation (DES) approach has been introduced, see Guilmineau et al. [19]. Recently, some modifications of this formulation proposed by Griskevich et al. [26] include recalibrated empirical constants in the shielding function and a simplification of the original Spalart-Allmaras-based formulation. This new model is called Improved Delayed Detached Eddy Simulation (IDDES).

All flow variables are stored at the geometric center of arbitrary shaped cells. Volume and surface integrals are evaluated with second-order accurate approximations. The method is face-based, which means that the net fluxes in the cells are computed face by face. Thus, the cells with an arbitrary number of arbitrarily shaped faces are accepted. Numerical fluxes are reconstructed on the mesh faces by linear extrapolation of the integrand from the neighboring cell centers. A centered scheme is used for the diffusion terms, whereas for the convective fluxes, a blended scheme with $95 \%$ central differences and $5 \%$ upwind differences (for hybrid RANS-LES models), or $80 \%$ central and $20 \%$ upwind (for RANS models), is used. A central differencing scheme may become unstable for high values of the cell Reynolds number, and a upwind differencing scheme tends to introduce numerical diffusion. This is particularly problematic with LES. The low value of the upwind scheme is to prevent instabilities. For the convective flux, a blend of $95 \%$ central differences and $5 \%$ of upwind differences 
has also been used for LES in automotive flows [27].

The velocity field is obtained from the momentum conservation equations and the pressure field is extracted from the mass conservation constraint or continuity equation, transformed into a pressure-equation. The pressure equation is obtained by the Rhie and Chow interpolation [28]. The momentum and pressure equations are solved in an segregated manner as in the SIMPLE coupling procedure [29]. A detailed description of the discretization is given by [30].

\subsection{Turbulence modelling}

RANS results shown in this paper are obtained using two turbulence models: the classical two-equation SST model of Menter [31] $(k-\omega$ SST) and the anisotropic two-equation Explicit Algebraic Reynolds Stress Model (EARSM) [25]. The $k-\omega$ SST model is a $k-\omega$ based model which has the addional ability to account for the transport of the principal shear stress in adverse pressure gradient boundary layers. The EARSM model is the most reliable statistical turbulence modelling for predicting three-dimensional flows such as ship flows when intense longitudinal vortices spread out in the aft part of the ship. For this turbulence model, the turbulent velocity and length scales are determined by using two transport equations, the $k-\omega$ BSL model proposed by Menter [31].

The hybrid RANS-LES methods are based on an implicit splitting of the computational domain into two zones. In the first region near the solid walls, the conventional RANS equations are solved. In the second region, the governing equations are the filtered Navier-Stokes equations for the LES approach. One hybrid RANS-LES method is the Detached Eddy Simulation (DES), originally based on the Spalart-Allmaras one equation RANS model [1]. However, the hybrid nature of DES is not linked with any specific turbulence model and the model employed in the present study is a variant based on the $k-\omega$ SST turbulence model proposed by Strelets [32]. The dissipation term in the $k$ equation, $D_{k}$, is modified in order to reduce the eddy-viscosity in LES regions and is written as:

$$
D_{k}=\beta^{*} \rho k \omega F_{\mathrm{DES}}
$$


where $\beta^{*}$ is a constant of the SST model, $k$ is the turbulent kinetic energy, $\omega$ is the specific dissipation rate of turbulent frequency and $F_{\mathrm{DES}}$ is a function defined by

$$
F_{\mathrm{DES}}=\max \left(\frac{L_{\mathrm{RANS}}}{C_{\mathrm{DES}} \Delta}, 1\right)
$$

where $\Delta$ is the maximum local grid spacing $(\Delta=\max (\Delta x, \Delta y, \Delta z)), L_{t}$ is the turbulent length scale, $L_{\mathrm{RANS}}=\sqrt{k} /\left(\beta^{*} \omega\right)$ and $C_{\mathrm{DES}}$ is a constant.

The second hybrid RANS-LES method used is the Improved Delayed DetachedEddy Simulation (IDDES) which combines Delayed Detached-Eddy Simulation (DDES) and wall-modelled LES length-scale according to Shur et al. [20] in the following manner:

$$
\begin{aligned}
& D_{k}=\rho \sqrt{k^{3}} / L_{\mathrm{IDDES}} \\
& L_{\mathrm{IDDES}}=\tilde{f}_{d}\left(1+f_{e}\right) L_{\mathrm{RANS}}+\left(1-\tilde{f}_{d}\right) L_{\mathrm{LES}}
\end{aligned}
$$

where the length scale $L_{L E S}$ is defined as $C_{\mathrm{DES}} \Delta$. The grid scale $\Delta$ is defined as $\min \left[\max C_{w}\left(\Delta_{\max } ; d\right) ; \Delta_{\max }\right]$ with $C_{w}$ being a constant, $d$ the distance to the nearest wall and $\Delta_{\max }$ is equal to $\max (\Delta x, \Delta y, \Delta z)$. The function $\tilde{f}_{d}$ is defined as $\max \left[1-f-d t, f_{B}\right]$ which is determined by both the geometry part $f_{B}$ and the flow part $\left(1-f_{d t}\right)$. The detailed formulations of functions $f_{B}, f_{d}, f_{d t}, f_{e}$ can be found in the paper of Griskevich et al. [26]. The IDDES model provides a more flexible and convenient scale-resolving simulation model for high Reynolds number flows. Because IDDES combines DES and wall-modeled LES, this new model help in solving the grid-induced separation as it increases the modeled stress contribution across the interface.

\section{Numerical simulation set-up}

For both slant angles, the computational domain starts $7.250 H$ in front of the model and extends to $18.125 \mathrm{H}$ behind the model. The width of the domain is $6.493 H$ and its height is $4.861 H$. These dimensions are recommended for the ERCOFTAC workshop on Refined Turbulence Modelling [6], and the cross section of the channel is identical to the open test section of the wind tunnel 
used in the experiments [22]. These dimensions of the computational domain implies a blocking factor equal to $4.28 \%$. Keogh et al. [33] showed that the blockage ratio plays an important role in the prediction of the drag coefficient.

The mesh is generated using Hexpress ${ }^{\mathrm{TM}}$, an automatic unstructured mesh generator. This software generates meshes containing only hexahedrals. For the car model and the floor, a no-slip boundary condition is used and the wall normal resolution is set to $0.007 \mathrm{~mm}$ which is below the $\eta_{n w}$ length, see Table 1 . A first refinement box is added around the back of the model, in which the sizes of the cell are $\Delta x=\Delta y=\Delta z=1.8 \mathrm{~mm}$. A second box including all the Ahmed body is also added. In this box, the cell sizes are $\Delta x=\Delta y=\Delta z$ $=3.6 \mathrm{~mm}$. From these cell sizes, it can be seen that the grid has its smallest cells of the same order as the Taylor scale. Thus, according to Howard and Pourquie [23], the grid is appropriate for the precision required for LES and for DES simulations. A view of the mesh is given in Figure 2. For the $25^{\circ}$ slant angle, the mesh contains $23.1 \times 10^{6}$ cells and the model is described by 384,090 faces. For the $35^{\circ}$ slant angle, the mesh consists of $22.2 \times 10^{6}$ cells and the model is described by 379,358 faces.

The mesh is the fine mesh used by Guilmineau et al. [19] to investigate the flow around the Ahmed body with a DES approach. In this paper, three meshes, containing 7.5, 12.3 and 23.6 million nodes, were used to a mesh convergence. Figure 3 presents the time-averaged streamwise velocity component and the turbulent kinetic energy, obtained with the IDDES model, on the slanted surface, versus the mesh used for the $25^{\circ}$ slant angle. Small discrepancies, and particularly at the end of the slanted surface, exist but the solution between the results, obtained with the medium mesh and the fine mesh, are very similar. Table 2 presents the drag coefficient for the DES model and the IDDES model for the three meshes for the $25^{\circ}$ slant angle. The variation between the results obtained with the medium and fine meshes is $0.5 \%$ for the DES model and $2.6 \%$ for the IDDES model. Then, the fine mesh is used for the simulation with the other turbulence models.

To capture the possible unsteadiness of the mean flow, unsteady simulation 


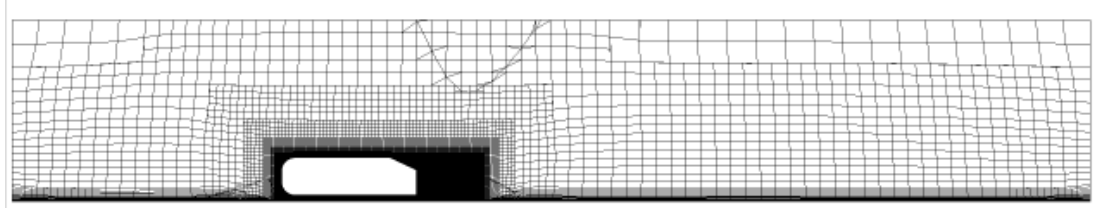

(a) General view

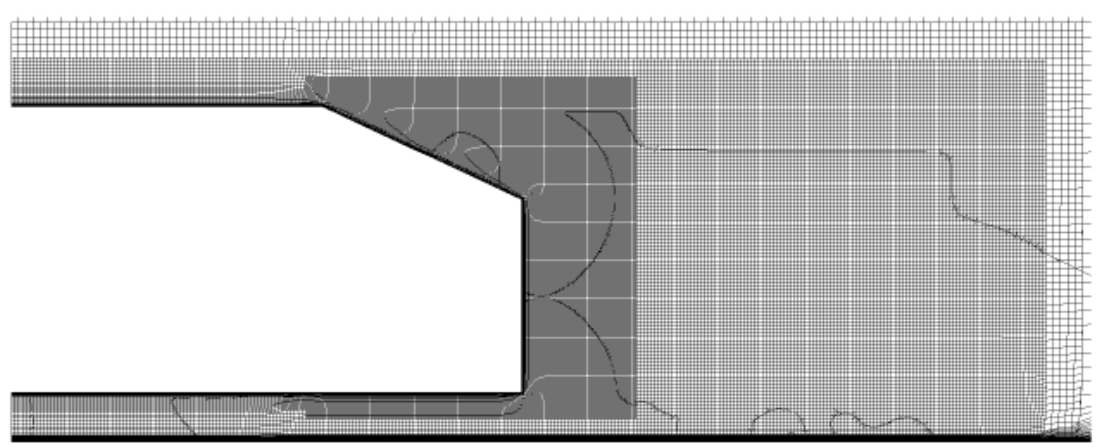

(b) Zoom at the back of the model

Figure 2: View of the mesh in the symmetry plane for the $25^{\circ}$ slant angle.

Table 2: Drag coefficient obtained with the DES and IDDES models versus the mesh for the $25^{\circ}$ slant angle.

\begin{tabular}{lccc}
\hline & Coarse mesh & Medium mesh & Fine mesh \\
\hline DES & 0.411 & 0.415 & 0.417 \\
IDDES & 0.344 & 0.390 & 0.380 \\
\hline
\end{tabular}

are carried out with the RANS turbulence models. In this case, the time step is $\Delta t=0.001 \mathrm{~s}$. However, it is observed that the numerical simulations converge to a steady flow. With the hybrid RANS-LES models, the flow is by nature unsteady and the time step is $\Delta t=2.5 \times 10^{-4} \mathrm{~s}$. With these models, the averaging time, $\mathrm{t} U_{\infty} / \mathrm{H}$, in the simulation is approximately 150 .

\section{Results}

In this section, the numerical results obtained with the four turbulence models for both slant angles are compared with the experimental data obtained by 


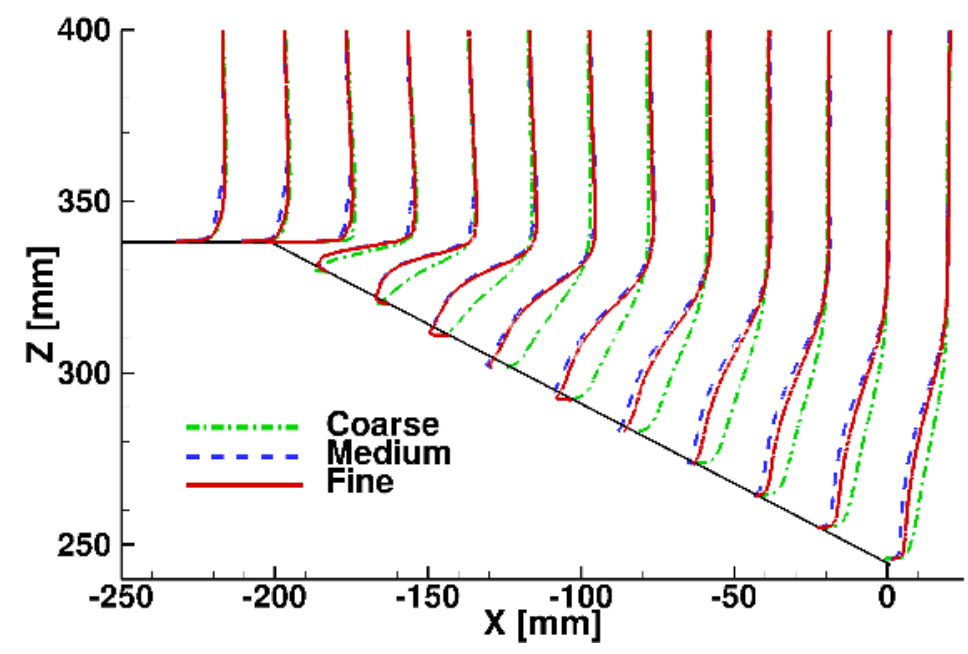

(a) Streamwise velocity component

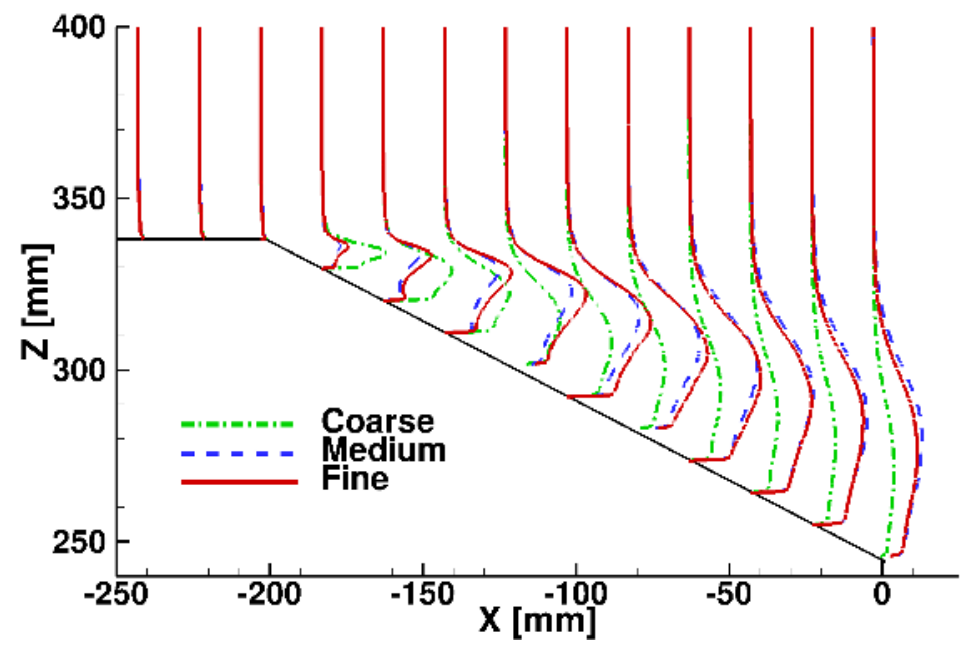

(b) Turbulent kinetic energy

Figure 3: Time-averaged profiles obtained with the IDDES model in the symmetry plane for the $25^{\circ}$ slant angle.

Lienhart and Becker [22]. The results obtained with the hybrid RANS-LES models and presented in this section show the mean flow. 


\section{1. $35^{\circ}$ slant angle}

Figure 4 shows the vortex structures by means of the dimensionless $\lambda_{2}$ of the second largest invariant of $\mathbf{S}^{2}+\boldsymbol{\Omega}^{2}, \mathbf{S}$ and $\boldsymbol{\Omega}$ being the symmetric and antisymmetric component of $\nabla \mathbf{u}$, for the Ahmed body with the $35^{\circ}$ slant angle. All turbulence models predict a separation on the rear slant. However, the shape is not the same according to the turbulence model used. A longitudinal vortex along the bottom edge of the model is predicted by all simulations.

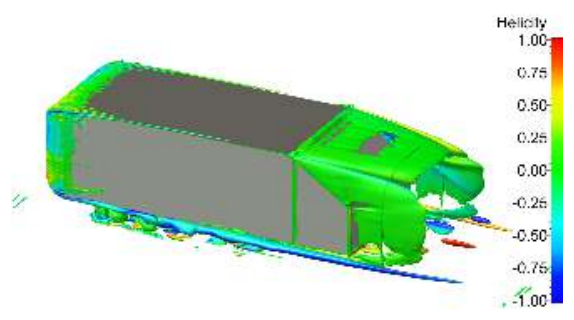

(a) $k-\omega \mathrm{SST}$

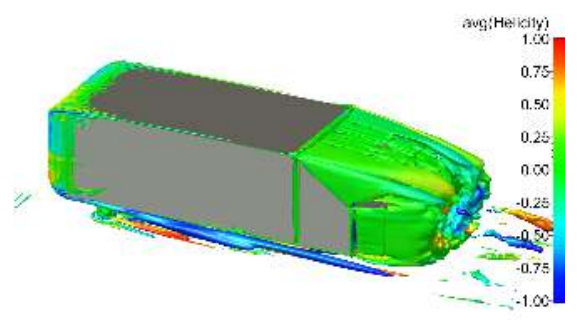

(c) DES

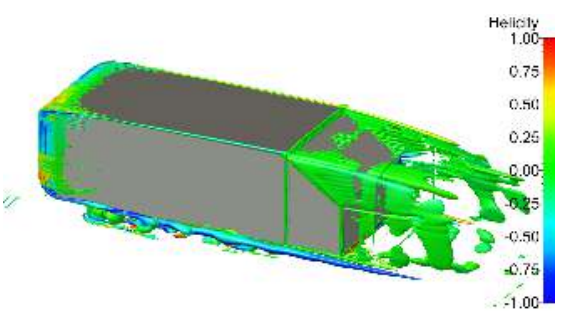

(b) EARSM

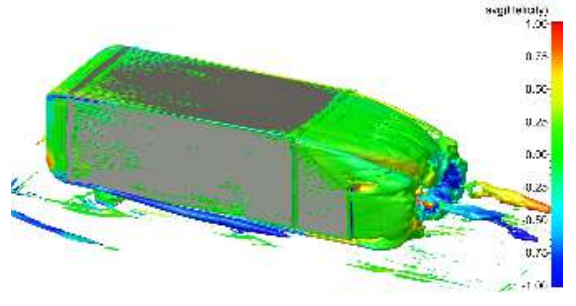

(d) IDDES

Figure 4: $35^{\circ}$ slant angle - Vortex structures around the Ahmed body visualized by iso-surface of non-dimension $\lambda_{2}\left(\lambda_{2}=0.76\right)$.

Figure 5 presents the friction lines on the model for all turbulence models used. At first glance, two categories may be distinguished depending on the turbulence model type, namely RANS or hybrid RANS-LES. With a RANS turbulence model, the flow is fully separated on the rear slant. At the base of the model, the trace of two counter-rotatiing structures is present. With a hybrid RANS-LES model, the pattern of the rear slant is different. The flow is separated at the upstream edge of the slant but another separation is predicted 
at the end of the body. With the IDDES approach, the flow separates at the front end of the body as it reaches the roof, the lateral, and the bottom sides of the body.

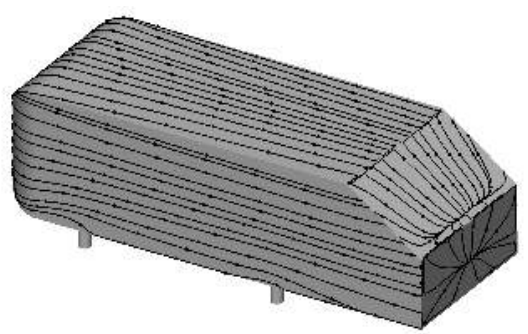

(a) $k-\omega \mathrm{SST}$

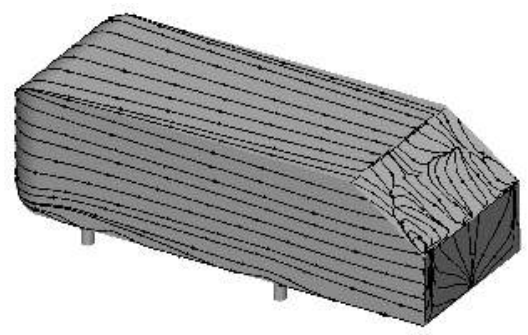

(c) DES

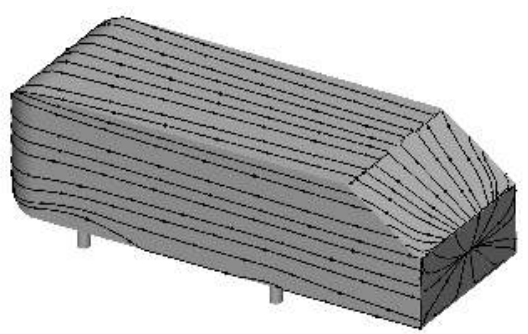

(b) EARSM

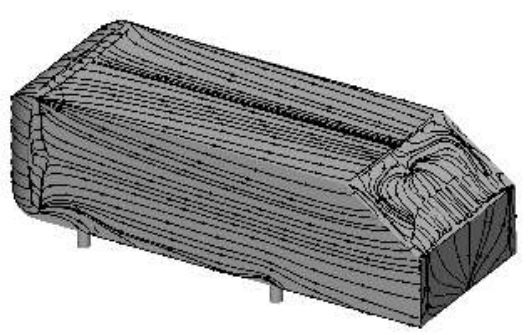

(d) IDDES

Figure 5: $35^{\circ}$ slant angle - Friction lines on the model. ported in Figure 6 together with the experimental results. The main characteristic of this flow is a massive separation in the wake of the body. With the EARSM turbulence model, this separation is largest while with the IDDES, the recirculation is the smaller which is in much better agreement with the experiments. With the hybrid RANS-LES models, a small separation is observed at the end of the slant. In the experiments, it is difficult to say if this recirculation is present. With the RANS models, the lowest separation is almost non-existent. due to the size of the upper separation. With the hybrid RANS-LES models, the size of the lowest separation varies according to the model used. The shape 
experimental data.

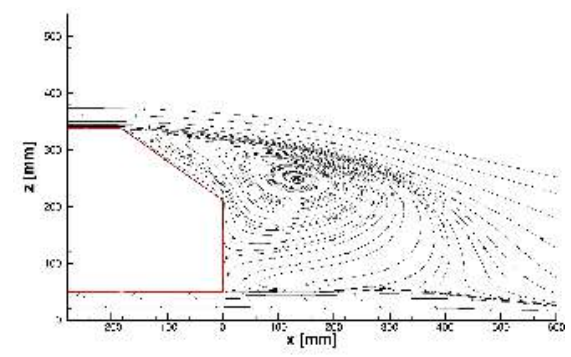

(a) $k-\omega \mathrm{SST}$

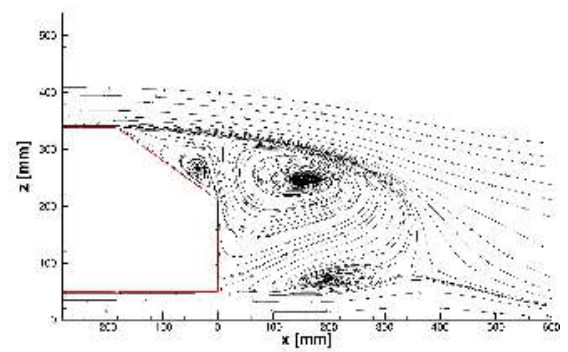

(c) DES

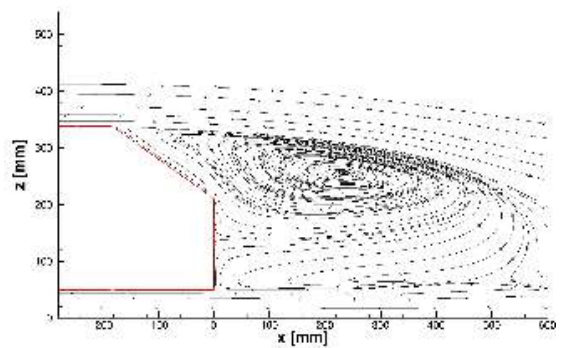

(b) EARSM

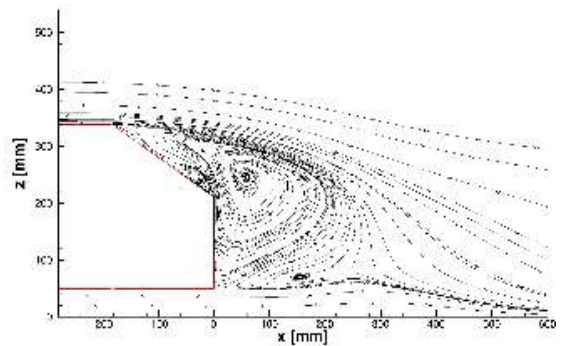

(d) IDDES

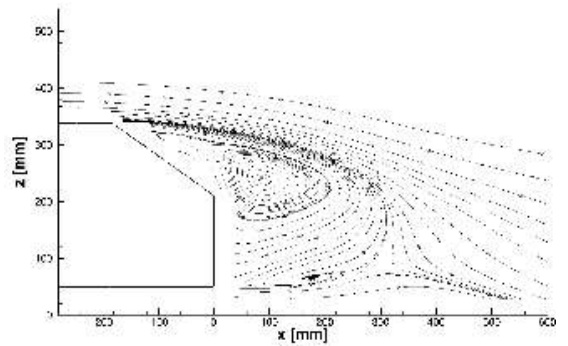

(e) Experiments

Figure 6: $35^{\circ}$ slant angle - Streamlines in the symmetry plane $\mathrm{Y}=0$.

A description of the wake is provided by plotting isocontours of the streamwise velocity in successive YZ-planes in the body wake, as reported in Figure 7. The massive separation is not limited to the symmetry plane. Indeed, at the end of the slant, the area where the streamwise velocity is negative covers the whole width of the model. This area extends far in the wake, and more particularly 
with the RANS turbulence models. At $\mathrm{X}=500 \mathrm{~mm}$, negative streamwise velocity is still observed with the RANS models, and particularly with the EARSM turbulence model. With the hybrid RANS-LES models, the recirculation region extends more than $200 \mathrm{~mm}$ but less than $500 \mathrm{~mm}$ as in experiments.

The turbulent kinetic energy (TKE) in the symmetry plane is indicated in Figure 8. The maximum TKE in experiments is located around the lowest separation in the wake of the model. The hybrid RANS-LES turbulence models predict similars results but the high values of TKE are more intense with the IDDES model and are in better agreement with the experiments. With the RANS turbulence models, the values of TKE are lower than those obtained with the hybrid RANS-LES models, even in the shear layer at the lowee edge of the recirculation region.

Figure 9 presents the production of the turbulent kinetic energy in the symmetry plane for all turbulence models. For the hybrid RANS-LES models, this term was reconstructed from the computed mean flow. In the wake of the body, the production of TKE is very strong for RANS models while with the hybrid RANS-LES models, the maximum production is located close to the shear layer of the separation. On the roof of the body, the region of strong TKE production is larger with a RANS model than with hybrid RANS-LES models. With the IDDES model, this region is very thin, not only above the roof but also at the underbody and on the floor. With the $k-\omega$ SST and DES models this region with a high TKE production is located in front of the body at about $\mathrm{X}=-1000$ $\mathrm{mm}$. With the other models, a maximum TKE production is located at the same position but the level is significantly lower. With the hybrid RANS-LES models, and more particularly with the IDDES model, a region with a high level of TKE production is located on the upper rounded part of the front.

Figure 10 provides a more quantitative comparison of the velocity along vertical lines in the symmetry plane for positions between $\mathrm{X}=-243 \mathrm{~mm}$ and $\mathrm{X}=-3 \mathrm{~mm}$, from left to right, where the space difference between two profiles is $\Delta \mathrm{x}=20 \mathrm{~mm}$. As showed previously, a massive separation is present over the rear slant and all turbulence models predict the correct flow. This is in 

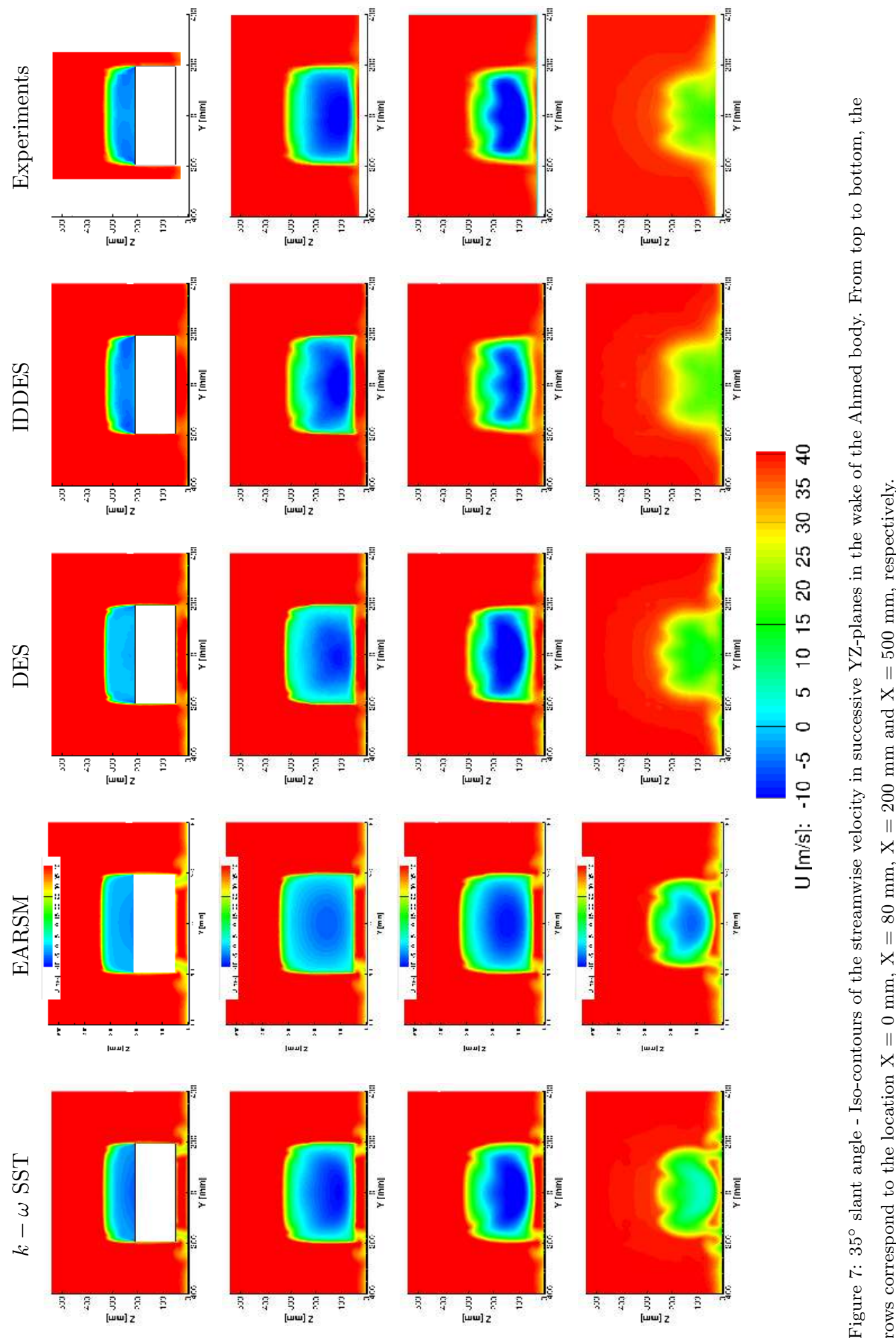


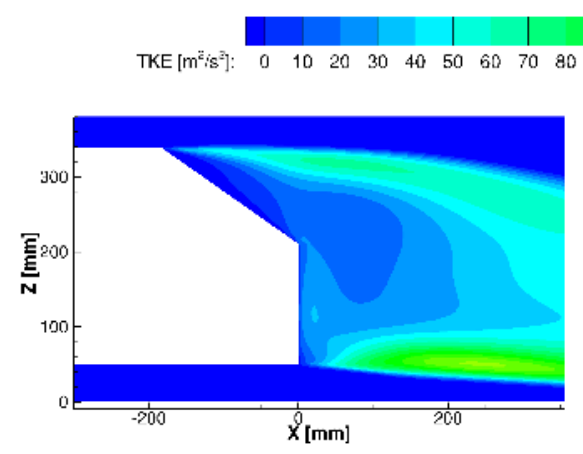

(a) $k-\omega \mathrm{SST}$

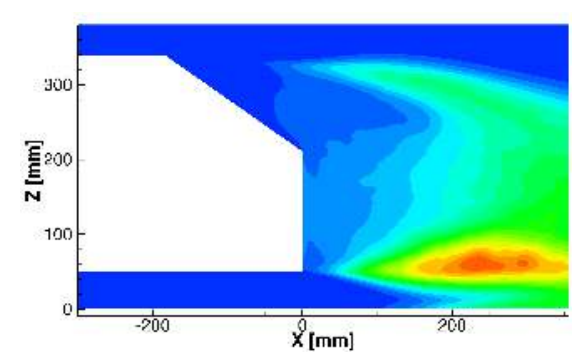

(c) DES

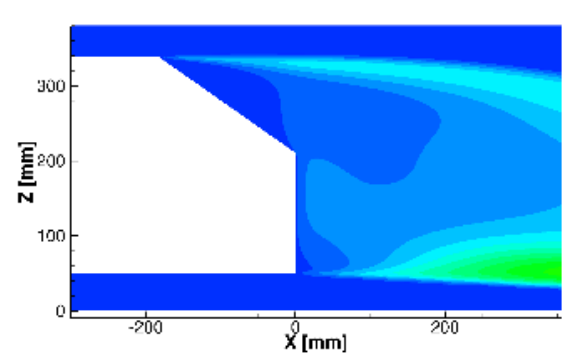

(b) EARSM

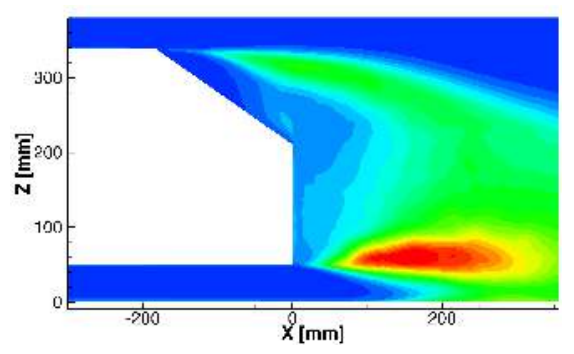

(d) IDDES

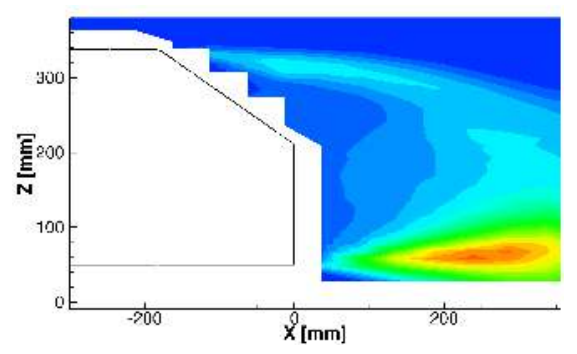

(e) Experiments

Figure 8: $35^{\circ}$ slant angle - Turbulent kinetic energy in the symmetry plane $\mathrm{Y}=0$.

agreement with many previous studies $[5,6]$ for which a variety of different turbulence models have been used. However, in this paper, the IDDES model gives a better agreement with the experimental data, particularly at the shear layer of the massive separation, see Figure 10(a).

A comparison of the velocity profiles in the wake of the model is presented 


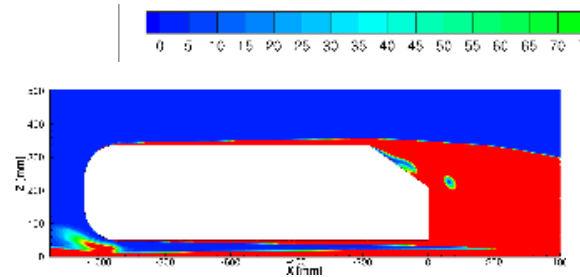

(a) $k-\omega \mathrm{SST}$

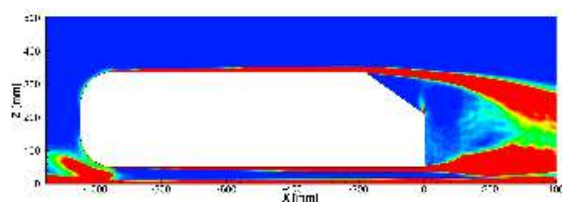

(c) DES

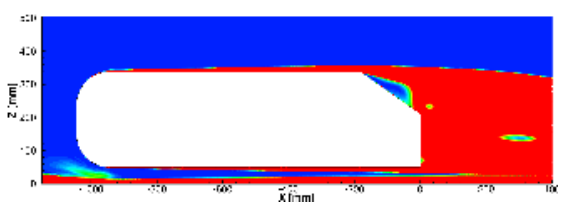

(b) EARSM

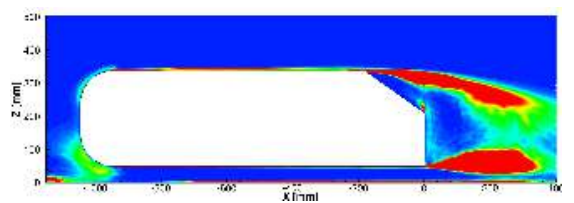

(d) IDDES

Figure 9: $35^{\circ}$ slant angle - Production of the turbulent kinetic energy in the symmetry plane $\mathrm{Y}=0$.

in Figure 11. The positions range from $\mathrm{X}=38 \mathrm{~mm}$ to $\mathrm{X}=338 \mathrm{~mm}$, from left to right, where the space difference between two profiles is $\Delta \mathrm{x}=50 \mathrm{~mm}$ and from $\mathrm{X}=338 \mathrm{~mm}$ to $\mathrm{X}=638 \mathrm{~mm}$ with a space $\Delta \mathrm{x}=100 \mathrm{~mm}$. All numerical simulations give a good agreement with the experimental data with the least good agreement for the EARSM turbulence model due to the size of the recirculation zone which is larger than that obtained with the other turbulence models. A difference between the profiles obtained with the RANS models and those obtained with the DES, shows the overestimation of the underbody flow with the RANS models.

Figure 12 presents a comparison of the turbulent kinetic energy (TKE) over the rear slant and in the wake. The numerical simulations are in agreement with the experimental data. On the slanted surface, the results obtained with the $k-\omega$ SST model are in good agreement with the experimental data while the results obtained with the IDDES model overestimated the experiments but only for the last threefour slices. With the other turbulence models, namely EARSM and DES, TKE is underestimated. In the wake, after $\mathrm{X}=200 \mathrm{~mm}$, all RANS turbulence models underestimate TKE at the level of the shear layer 


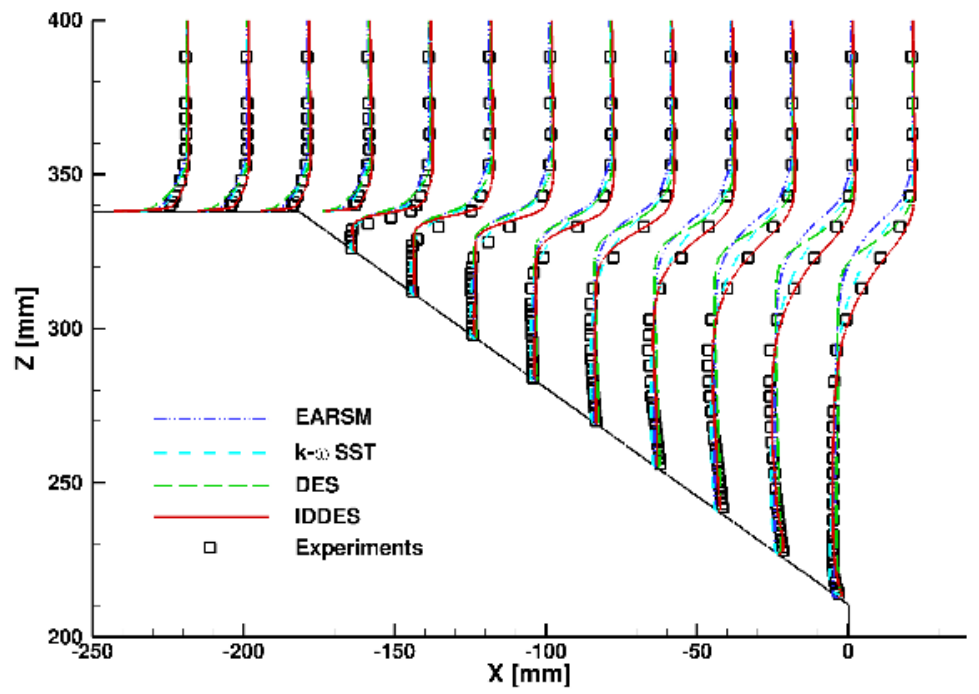

(a) Streamwise component

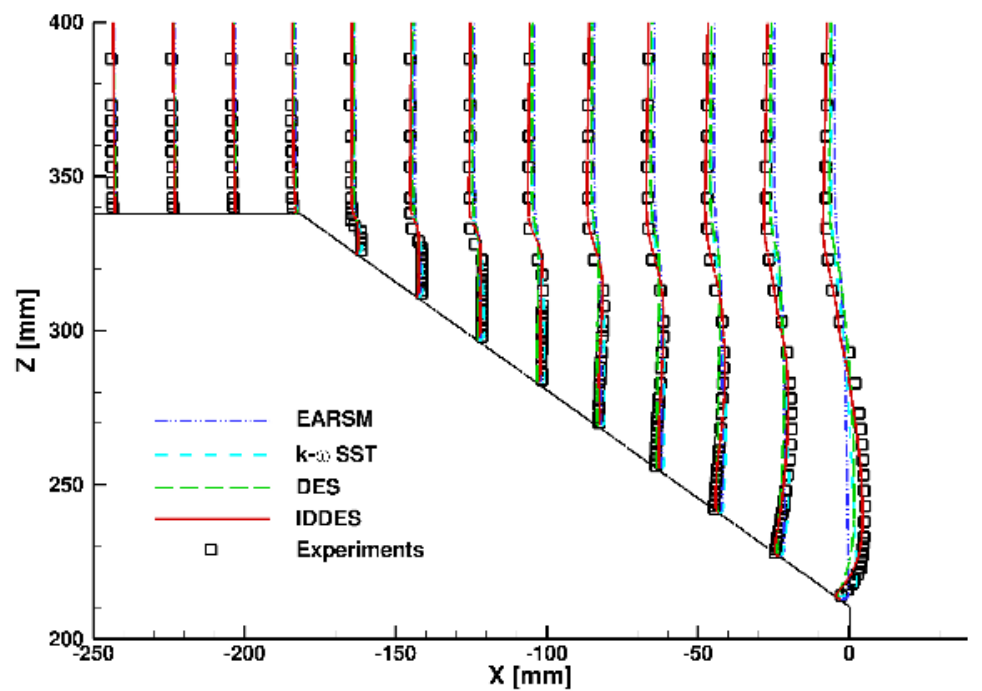

(b) Vertical component

Figure 10: $35^{\circ}$ slant angle - Velocity profiles on the slanted surface in the symmetry plane.

345 located at the bootom of the model. This is consistent with the overestimation of the velocity obtained with the RANS models. 


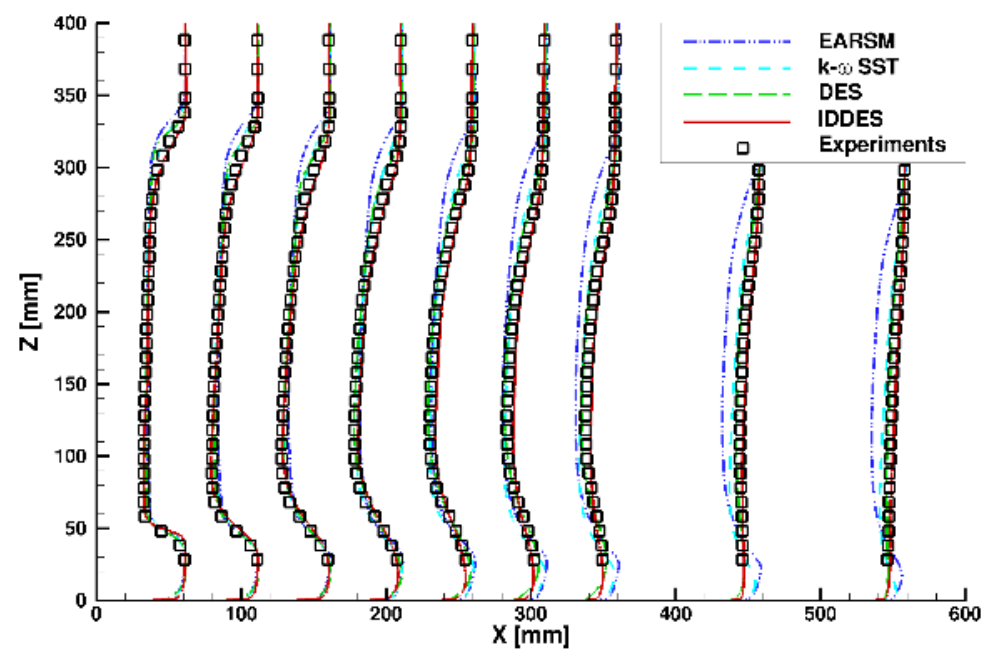

(a) Streamwise component

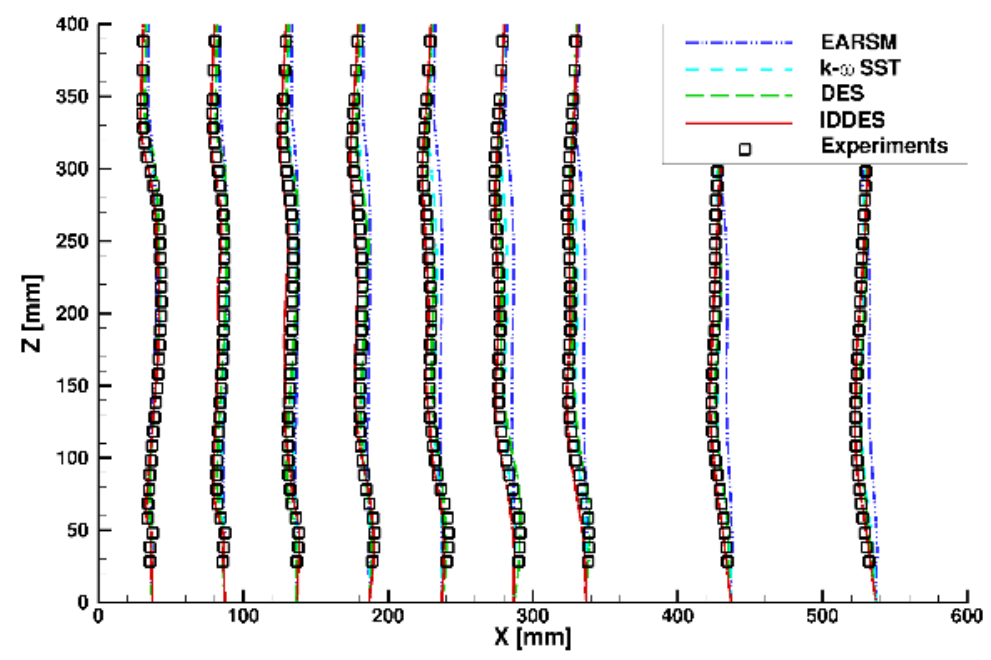

(b) Vertical component

Figure 11: $35^{\circ}$ slant angle - Velocity profiles in the wake in the symmetry plane.

A comparison of the streamwise velocity component and the turbulent kinetic energy in the plane $\mathrm{Y}=180 \mathrm{~mm}$, close to the maximum width of the model, is given in Figure 13. The profiles are for the same $\mathrm{X}$ positions as in the symmetry plane. However, the measurements are not available close to the wall. 


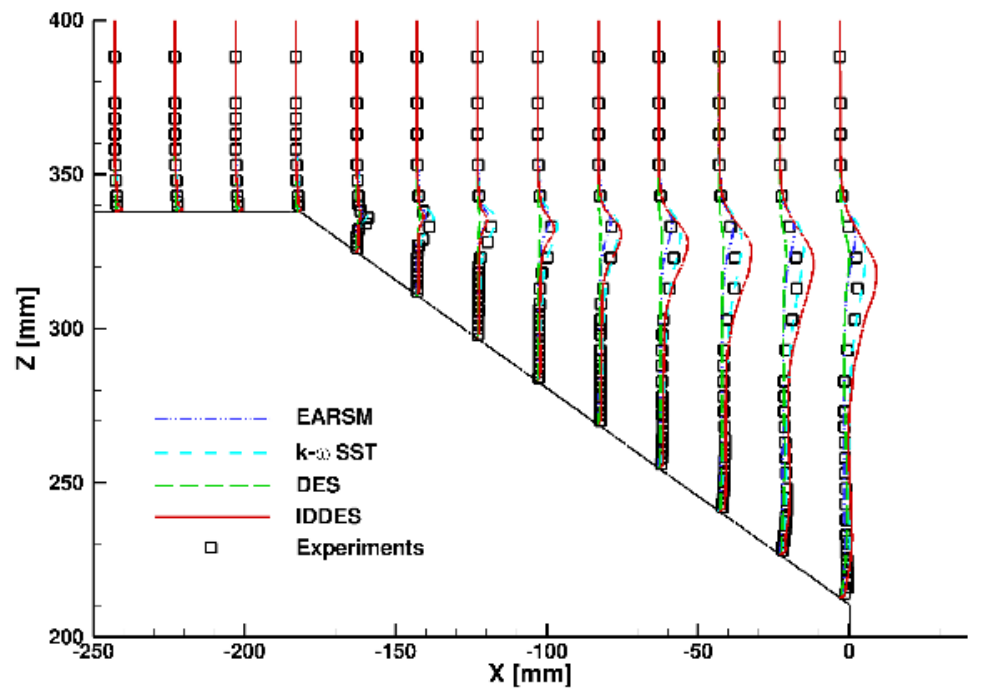

(a) On the slant

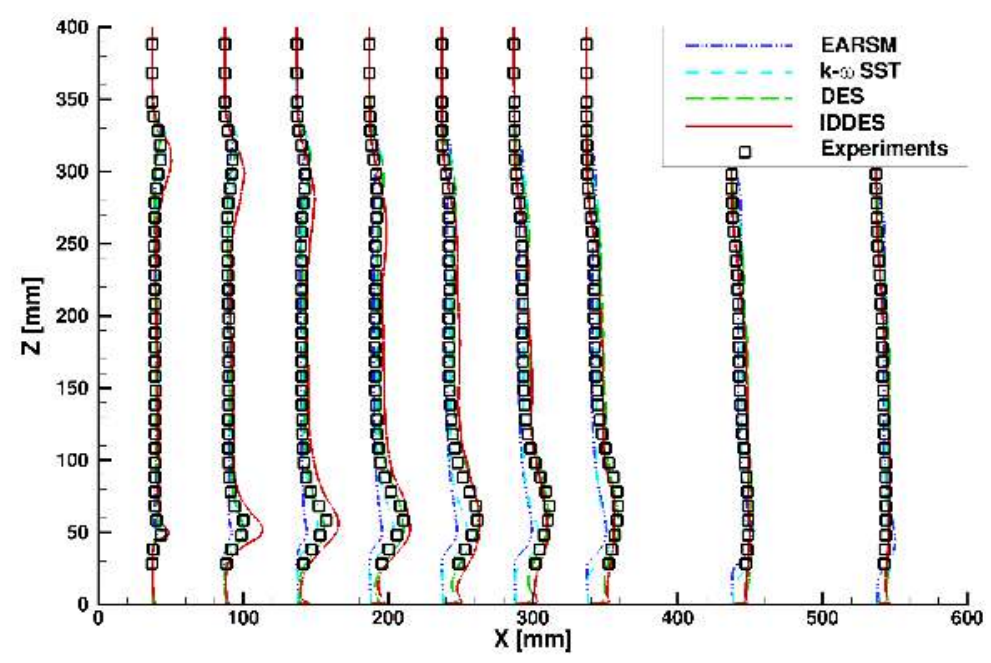

(b) In the wake

Figure $12: 35^{\circ}$ slant angle - Turbulent kinetic energy profiles in the symmetry plane.

All numerical simulations match the experiment data for the velocity profiles.

However, the best agreement with the experimental data is obtained with the IDDES turbulence model, even for the spanwise and vertical components which 
are presented in this paper. The other turbulence models overestimate the size of the separation. Again for the turbulent kinetic energy, the results obtained with the IDDES turbulence model are in good agreement with the experimental data.

Similar to what Ahmed et al. [4] did, the pressure drag for the front, $C_{K}$, for the rear slant, $C_{S}$ and for the base of the model, $C_{B}$, see Figure 14, are presented in Table 3. In this table, the experimental pressure values of Ahmed et al. [4] are also given. The ratio of each part compared to the total pressure drag, $C_{D, P}$, is also indicated. For this slant angle, the force on the rear slant surface, $C_{S}$, is slightly above the force on the base of the model, $C_{B}$, in the experiments. For the numerical simulations, this is true only for the results obtained with the $k-\omega$ SST model and the IDDES approach. The contribution of the front drag coefficient, $C_{K}$, to the total pressure drag is smaller in the numerical simulations than in experiments. For the numerical simulations, this represents about $2 \%$ of the total pressure drag for the numerical simulations with a hybrid RANS-LES model while with a RANS turbulence model this value is about $4 \%$.

Table 3: $35^{\circ}$ slant angle - Pressure drag coefficient breakdown.

\begin{tabular}{lcccccc}
\hline Model & $C_{B}$ & $C_{B} / C_{D, P}[\%]$ & $C_{S}$ & $C_{S} / C_{D, P}[\%]$ & $C_{K}$ & $C_{K} / C_{D, P}[\%]$ \\
\hline$k-\omega$ SST & 0.1047 & 46.26 & 0.1125 & 49.92 & 0.0081 & 4.57 \\
EARSM & 0.0937 & 50.11 & 0.0848 & 45.33 & 0.0085 & 3.62 \\
DES & 0.1206 & 50.38 & 0.1126 & 47.03 & 0.0062 & 2.58 \\
IDDES & 0.1391 & 46.60 & 0.1531 & 51.27 & 0.0063 & 2.13 \\
Experiments [4] & 0.0890 & 44.28 & 0.0970 & 48.46 & 0.0150 & 7.46 \\
\hline
\end{tabular}

Table 4 shows the force coefficients for all numerical simulations. The values measured by Ahmed et al. [4] are also indicated and in this paper the upstream velocity is $60 \mathrm{~m} / \mathrm{s}$, so the Reynolds number, based on the height of the model, is 1.2 million which is higher than that used in this study. The results obtained by Meile et al. [34], for the same Reynols number used in this study, are also presented. In their experiments, their blockage ratio is $3.8 \%$, slightly lower than 


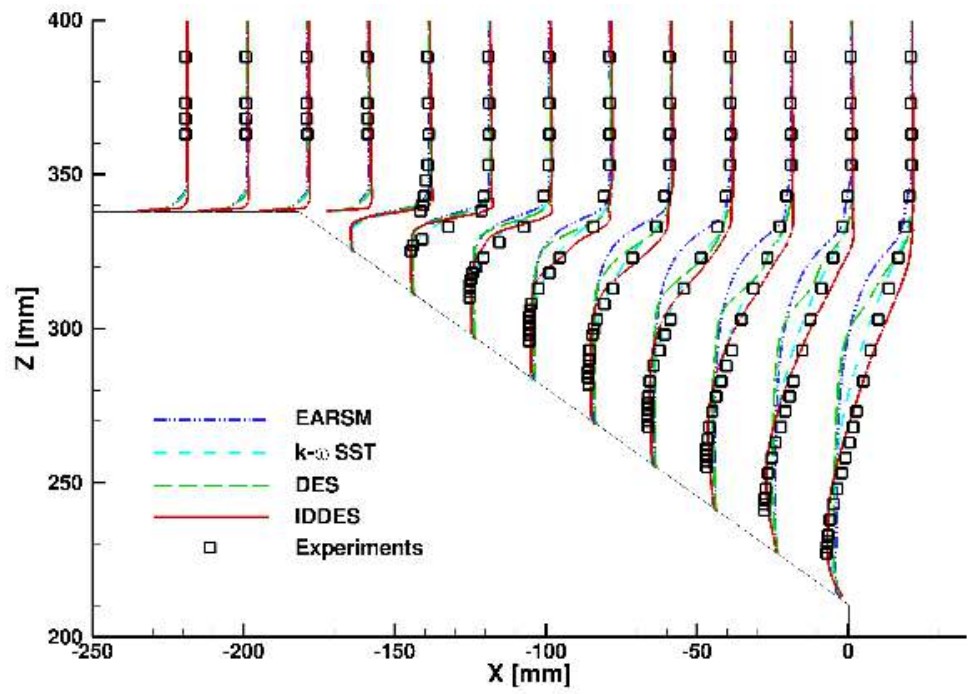

(a) Streamwise component

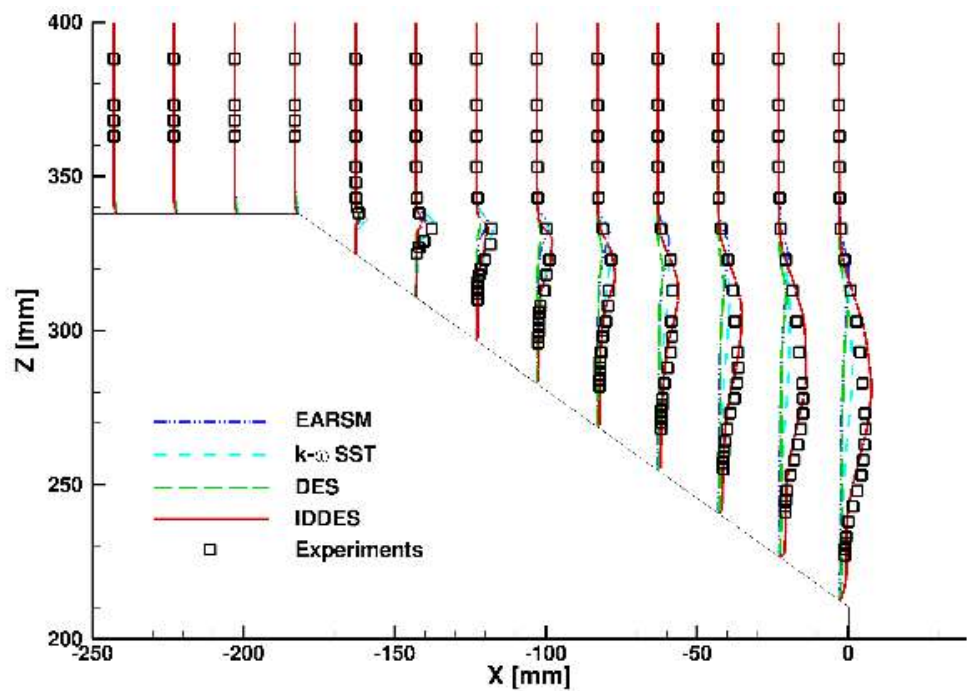

(b) Turbulent kinetic energy

Figure 13: $35^{\circ}$ slant angle - Velocity and turbulent kinetic energy profiles over the slanted surface in the plane $\mathrm{Y}=180 \mathrm{~mm}$. 


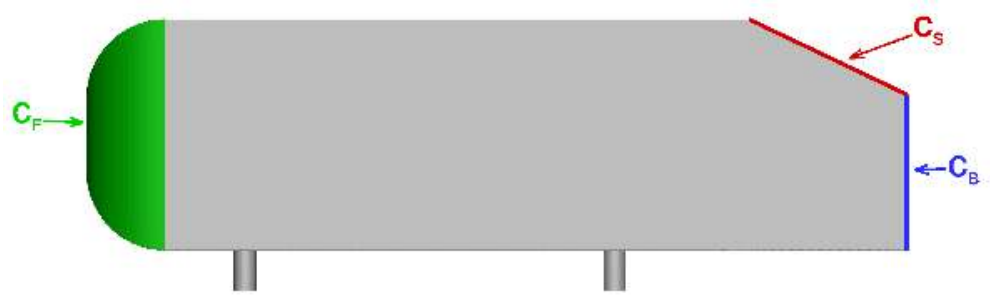

Figure 14: Representation of the pressure drag breakdown.

the value in the Ahmed's experiments. In the numerical simulations, the drag of feet represents about $10 \%$ of the total drag, except for the IDDES approach for which the drag due to the feet represents $8.5 \%$ of the total drag. All numerical simulations overpredict the drag coefficient compared with mesasurements by Ahmed et al. [4]. Another experiment [34] give a drag coefficient greater than that obtained by Ahmed et al. [4] but lower than those obtained by numerical simulations. All numerical simulations, excepted for the one using $k-\omega$ SST model, predict a negative lift coefficient. In the experiments of Meile et al [34], the lift coefficient is positive and close to the value obtained with the $k-\omega \mathrm{SST}$ turbulence model.

Table 4: $35^{\circ}$ slant angle - Drag and lift coefficients.

\begin{tabular}{ccccccc}
\hline & $k-\omega \mathrm{SST}$ & EARSM & DES & IDDES & Experiments [4] & Experiments [34] \\
\hline$C_{D}$ & 0.2999 & 0.2603 & 0.3156 & 0.3452 & 0.2580 & 0.2790 \\
$C_{L}$ & 0.0052 & -0.0388 & -0.0145 & -0.0145 & n.a. & 0.0040 \\
\hline
\end{tabular}

\section{2. $25^{\circ}$ slant angle}

Figure 15 shows the vortex structures by using a dimensionless isosurface of $\lambda_{2}$. The EARSM turbulence model does not see the modification of this new slant angle. Indeed, the shape of the separation seems to be very similar to that obtained with the $35^{\circ}$ slant angle, see Figure $4(\mathrm{~b})$, i.e. a massive separation. With the other turbulence models, the C-pillar vortices are predicted, but they are more pronounced with the IDDES approach which is the only turbulence 
model to predict the separation bubble on the slanted surface.

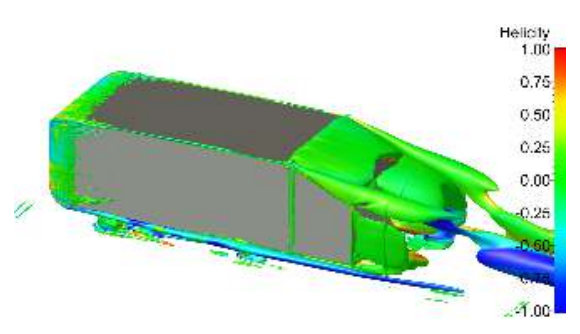

(a) $k-\omega \mathrm{SST}$

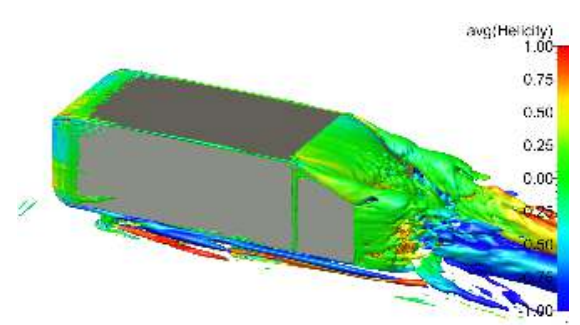

(c) DES

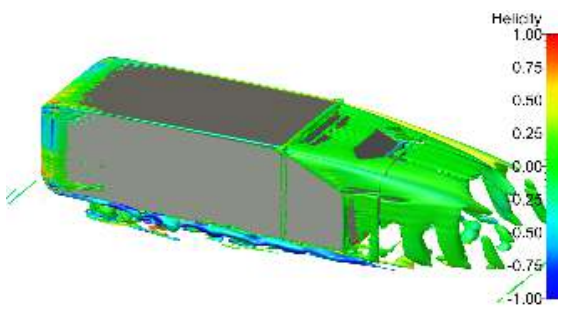

(b) EARSM

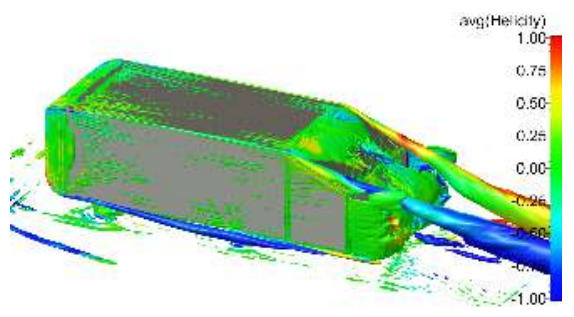

(d) IDDES

Figure 15: $25^{\circ}$ slant angle - Vortex structures around the Ahmed body visualized by iso-surface of non-dimension $\lambda_{2}\left(\lambda_{2}=0.76\right)$.

Figure 16 presents the friction lines on the walls of the model. With a RANS turbulence model, the pattern of the flow is different according to the turbulence model used, contrary to the results obtained for the $35^{\circ}$ slant angle. With the EARSM turbulence model, the flow is fully separated on the slant while with the $k-\omega$ SST model, the flow is separated on the slant but a vortex is also predicted at the level of the lateral edge of the model. With a hybrid RANSLES model, the sketch on the rear slant is approximately the same. The major difference is the position of the reattachment of the bubble on the slant. As for the $35^{\circ}$ slant angle, the flow predicted with IDDES separates at the front end of the body. This separation at the beginning of the roof has already been noted experimentally [35] but also numerically [16, 17].

Figure 17 shows the streamlines, in the symmetry plane, obtained for all turbulence models compared to the experimental data. With RANS turbulence 


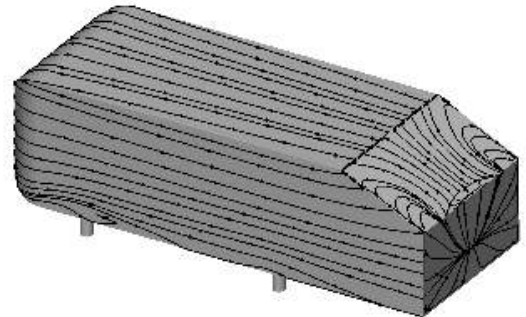

(a) $k-\omega \mathrm{SST}$

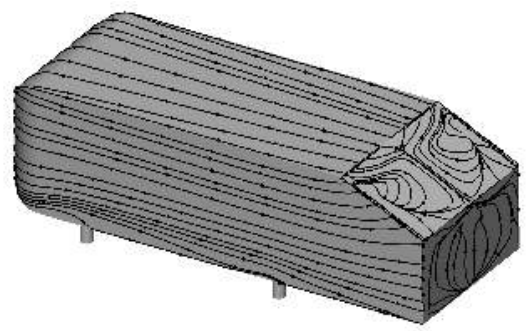

(c) DES

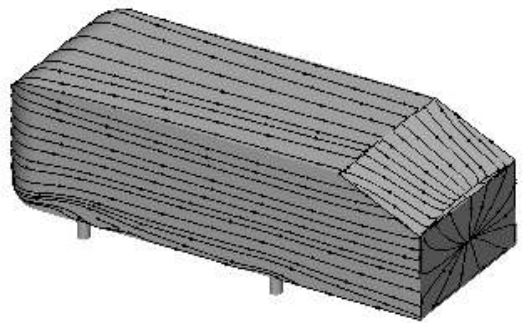

(b) EARSM

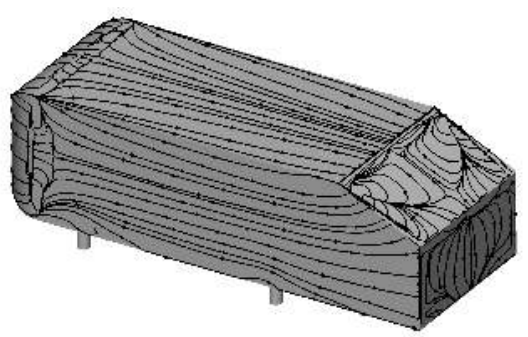

(d) IDDES

Figure 16: $25^{\circ}$ slant angle - Friction lines on the model.

models, a massive separation is obtained in the wake of the model. The flow separates on the rear slant and with the EARSM model, this separation is approximately the same as the one obtained with the $35^{\circ}$ slant angle. For the hybrid RANS-LES models, the wake is different. The massive separation does not exist, only small separations are present. On the slant, a recirculation bubble is predicted with the IDDES model while with the DES approach, this separation completely covers the slant. In the slant coordinate system, the reattachment point is located $168 \mathrm{~mm}$ from the upper edge of the rear slant surface with the IDDES approach. In the work of Thacker [36] at the same Reynolds number, this point is located at $160 \mathrm{~mm}$.

A comparison of the upstream velocity before the end of the model, $\mathrm{X}=$ $-38 \mathrm{~mm}$, and at the end of model is presented in Figure 18. In this figure, it is clear that the results obtained with the EARSM turbulence model do not 


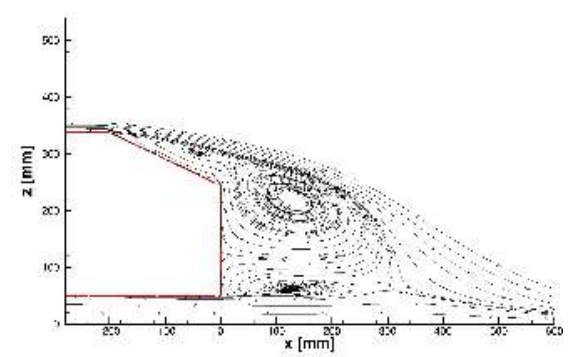

(a) $k-\omega \mathrm{SST}$

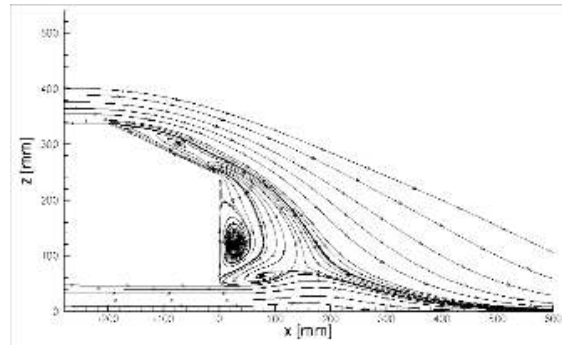

(c) DES

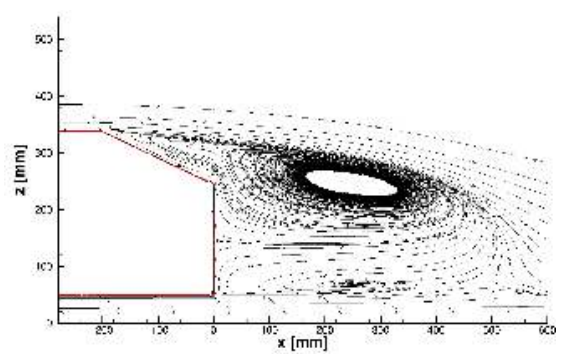

(b) EARSM

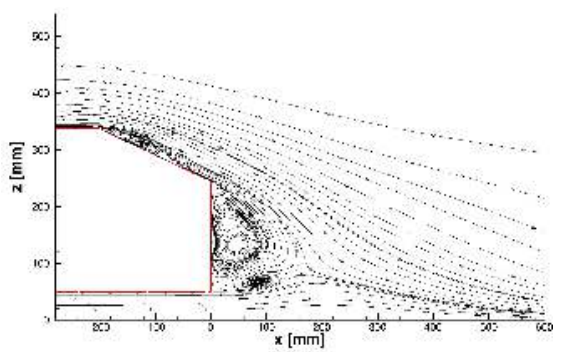

(d) IDDES

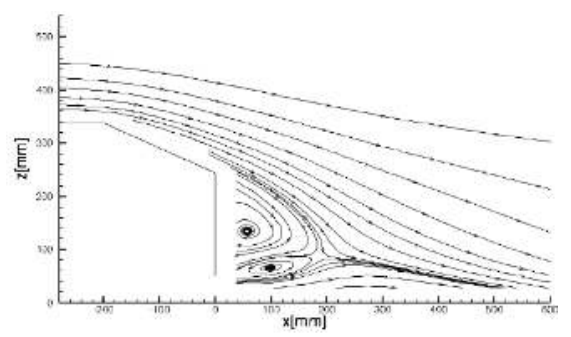

(e) Experiments

Figure 17: $25^{\circ}$ slant angle - Streamlines in the symmetry plane $\mathrm{Y}=0$.

a separation. With the $k-\omega$ SST turbulence model, the C-pillar vortex is present but its size is small because the separation on the slant is too large. With the DES approach, the size of the C-pillar vortex is in good agreement with the experiments but the velocity is the core of the vortex is too low. With the IDDES model, the size and the velocity in the core of the C-pillar vortex are well predicted and in agreement with the experimental data. 

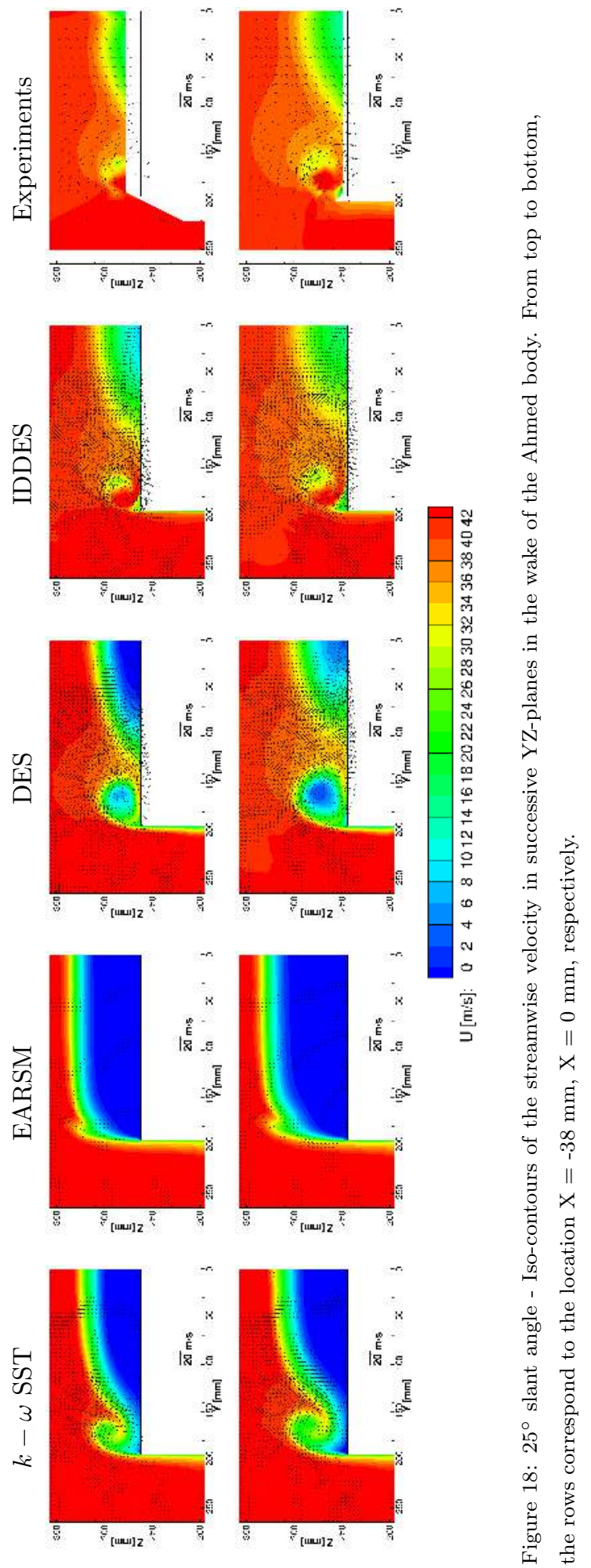
A description of the wake is presented in Figure 19 by plotting the streamwise velocity in successive YZ-planes in the body wake. With the RANS turbulence models, a massive separation is predicted, but the size of the separation is larger with the EARSM model than with the $k-\omega$ model. With these turbulence models, the computed wake is not correct regarding the measurements. With the $k-\omega$ model, the print of the cores of the trailing vortices is visible while with the EARSM turbulence model, due to the size of the speration, these prints are not visible. With the hybrid RANS-LES turbulence models, the wake prediction is in better agreement with the experiments. However, the simulation with the IDDES model gives a better prediction than the simulation with the DES model. At $\mathrm{X}=80 \mathrm{~mm}$, there is a strong region of recirculation back towards the model as in experiments while, with the DES model, this recirculation zone is much larger but with a weaker velocity. At $\mathrm{X}=200 \mathrm{~mm}$, the recirculation has been disappeared but there is still a large streamwise velocity deficit. At $\mathrm{X}=500 \mathrm{~mm}$, the C-pillar vortices can still be distinguished by the deficits in streamwise velocity, and the result obtained with the IDDES model is still in good agreement with the experimental data.

Figure 20 presents a comparison of the turbulent kinetic energy in the symmetry plane. As for the previous slant angle, a maximum of TKE is predicted in the shear layer of the lowest separation in the wake of the model with only the hybrid RANS-LES models. This maximum of TKE is in agreement with the experimental data. Compared to the $35^{\circ}$ slant angle, the maximum is located closer to the base of the model. With the RANS turbulence models, the maximum of TKE is also predicted at a similar position but the level is lower, particularly with the EARSM model. Another maximum of TKE is predicted by the hybrid RANS-LES models. This area is located over the slanted surface of the model. In the experiments, it is not clear whether this maximum exists because of the lack of resolution close to the model.

Figure 21 presents the production of the turbulent kinetic energy in the symmetry plane for all turbulence models used. As for the previous slant angle, the results obtained with the RANS models are very similar. In the wake of 

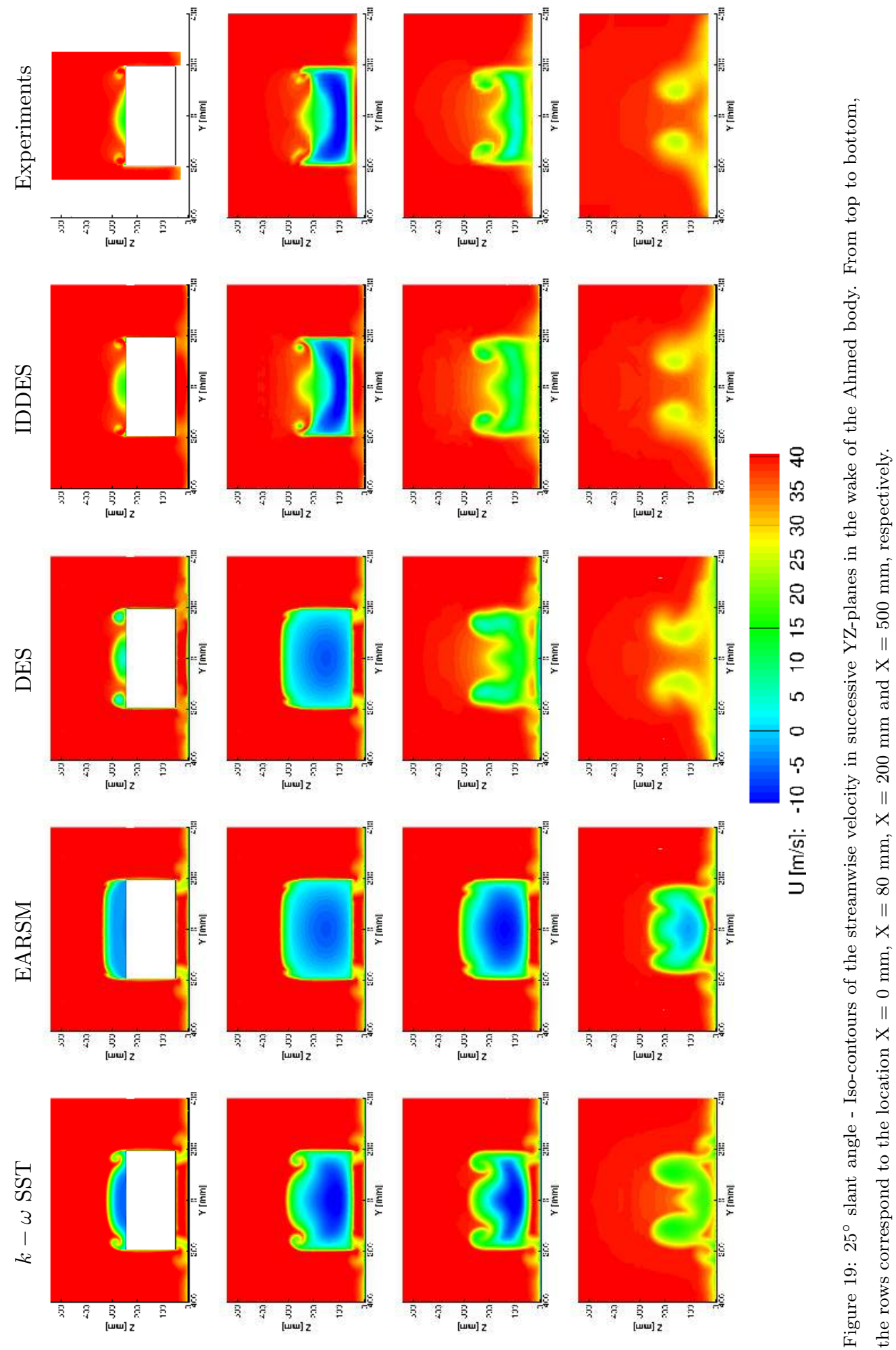


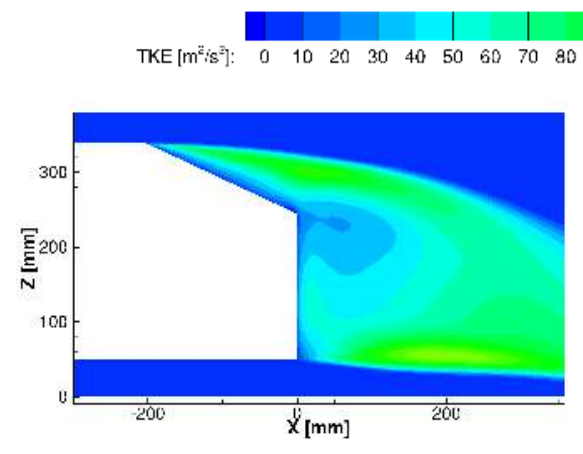

(a) $k-\omega \mathrm{SST}$

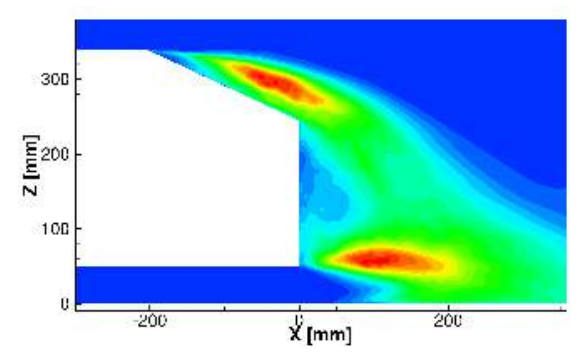

(c) DES

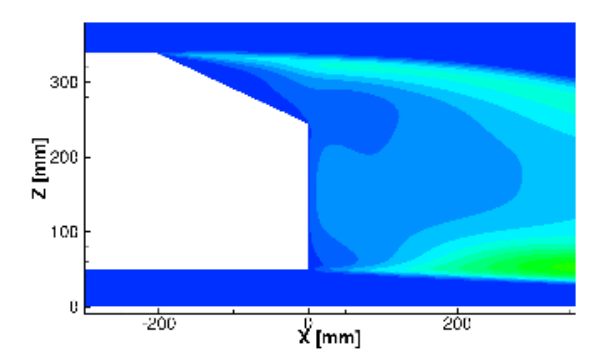

(b) EARSM

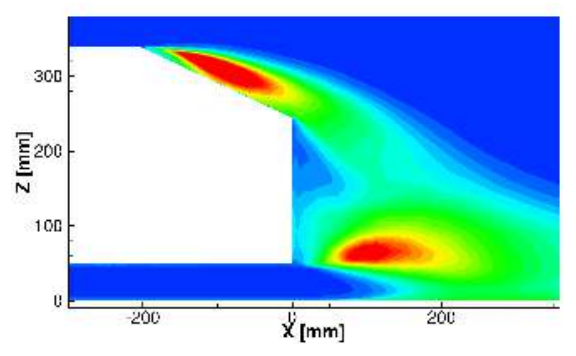

(d) IDDES

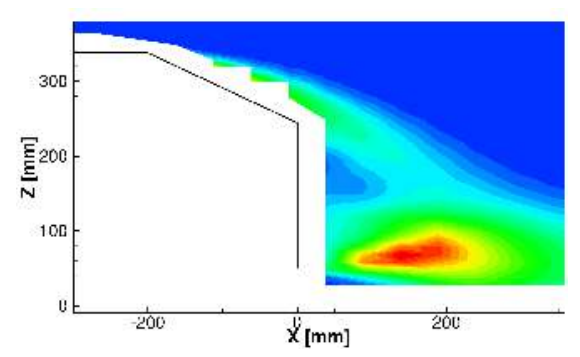

(e) Experiments

Figure 20: $25^{\circ}$ slant angle - Turbulent kinetic energy in the symmetry plane $\mathrm{Y}=0$.

the model, the production is very large. With a hybrid RANS-LES model, the maximum is located over the slant and in the shear layer of the lower recirculation in the wake. For the IDDES model, the region with a large value of TKE production along the roof, the underbody and the floor is finer than those obtained with the other turbulence models, as for the $35^{\circ}$ slant angle. On 
the upper rounded part of the front, a high value of production is obtained with the IDDES model.

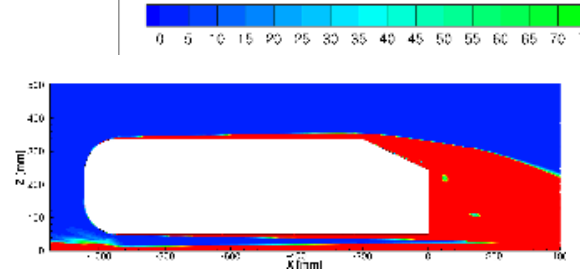

(a) $k-\omega \mathrm{SST}$

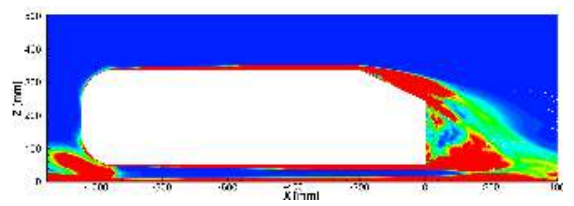

(c) DES

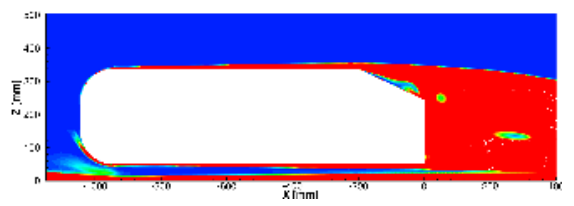

(b) EARSM

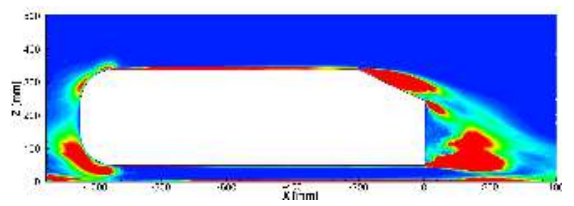

(d) IDDES

Figure 21: $25^{\circ}$ slant angle - Production of the turbulent kinetic energy in the symmetry plane $\mathrm{Y}=0$.

Comparisons of the velocity profiles on the slanted surface in the symmetry plane are presented in Figure 22. The profiles are for the same X position as for the $35^{\circ}$ slant angle. As expected, none of the RANS turbulence models gives a good agreement with the experimental data because of the massive separation. With the DES approach, the agreement with the experiments is better but the separation covers the entire slanted surface. The IDDES model is the only turbulence model to predict a separation bubble with a separation point close to the upstream edge and a reattachment point in the rear slant. The bubble separation is thicker in the numerical simulation than that obtained in the experiments. This is particularly true for the second and third planes in 475 the slanted surface.

Figure 23 shows a comparison of the velocity profiles in the wake of the model and in the symmetry plane for the same $\mathrm{X}$ positions as for the $35^{\circ}$ slant angle. As the RANS turbulence models predict a massive separation, the agreement with the experimental data are not good. With the hybrid RANS-LES turbulence 


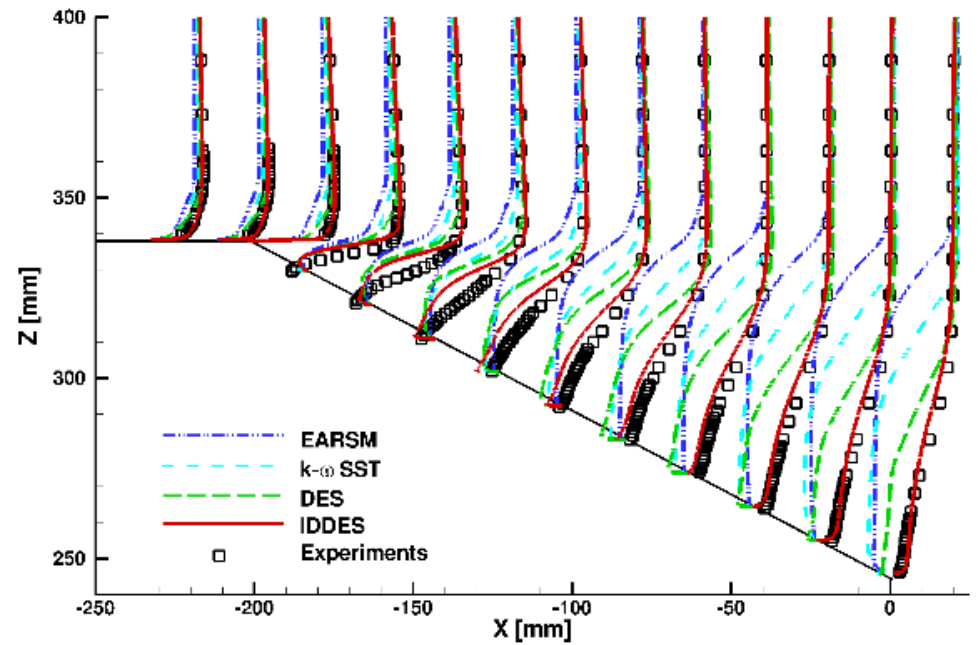

(a) Streamwise component

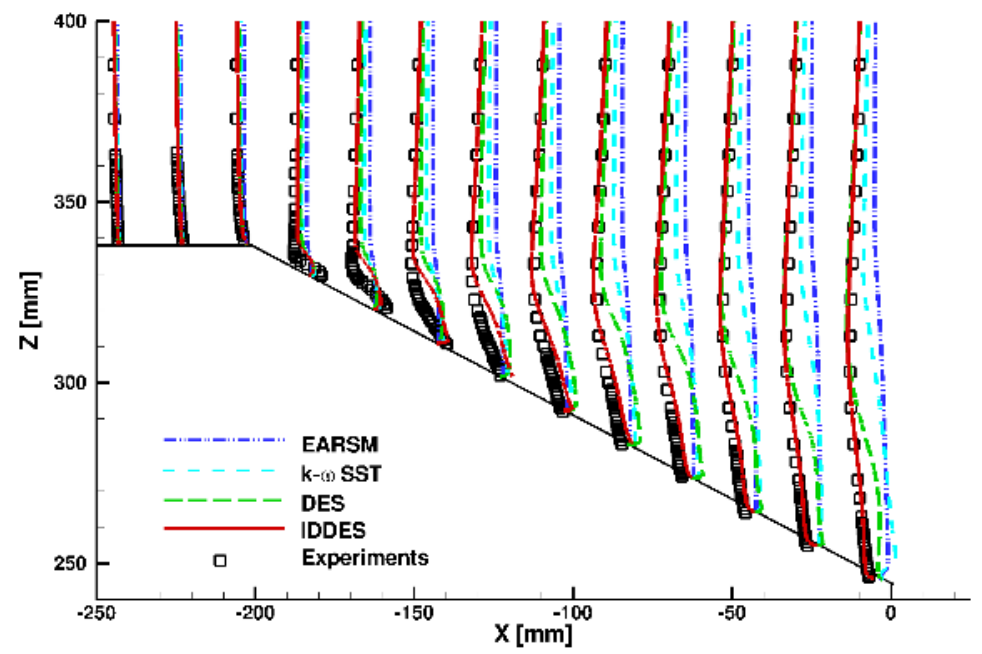

(b) Vertical component

Figure 22: $25^{\circ}$ slant angle - Velocity profiles on the slanted surface in the symmetry plane.

480

models, as the separation is smaller, the results are in better agreement with the experiments. The results obtained with the IDDES approach match very well the experimental data.

Figure 24 presents a comparison between experimental and numerical turbu- 


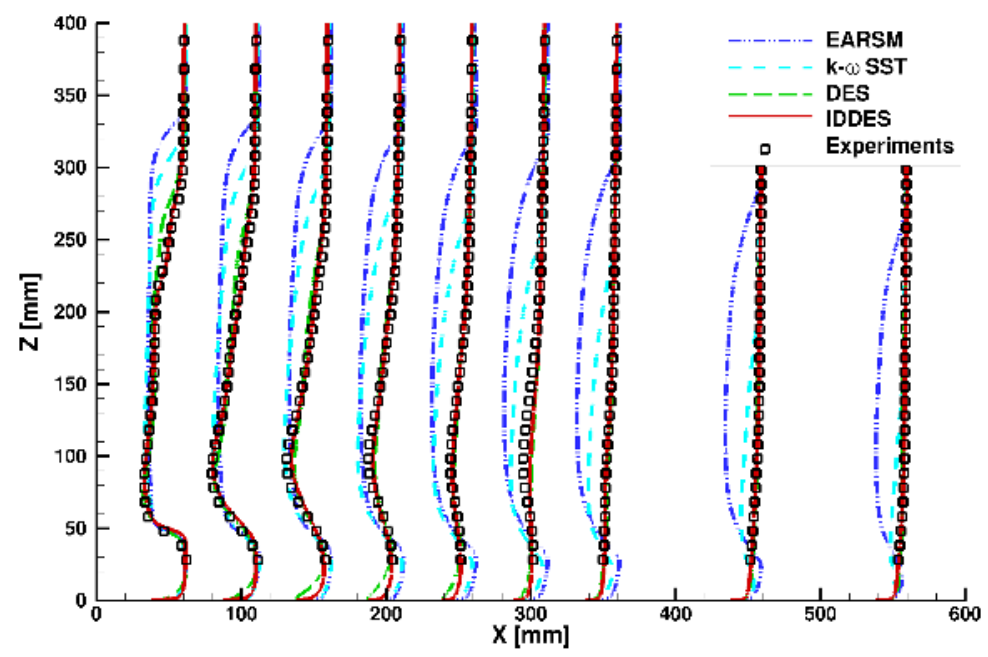

(a) Streamwise component

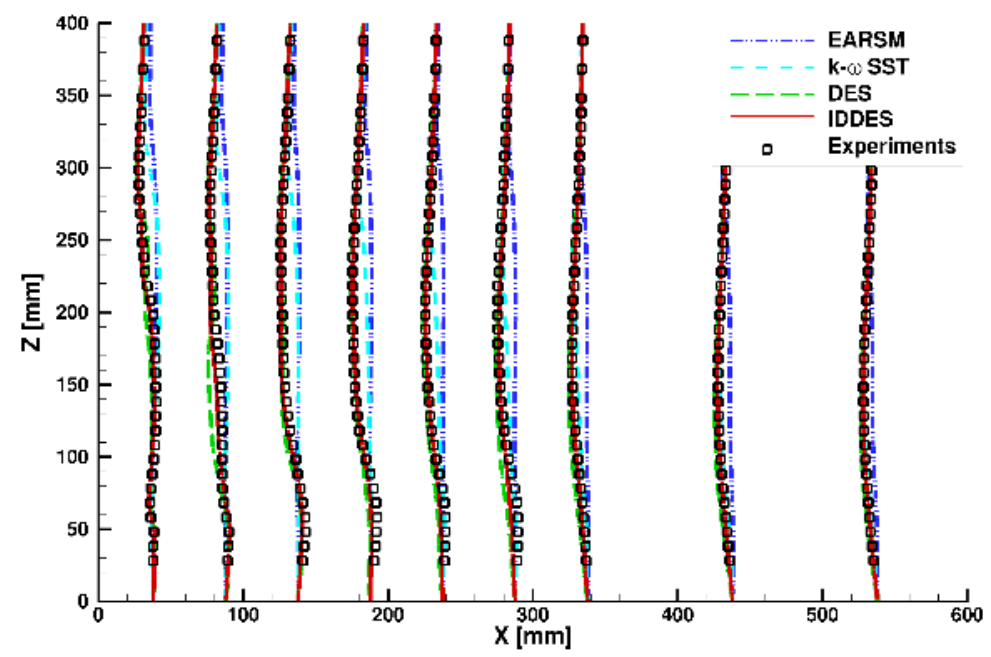

(b) Vertical component

Figure 23: $25^{\circ}$ slant angle - Velocity profiles in the wake in the symmetry plane.

lent kinetic energy in the symmetry plane. With the RANS turbulence models, 485 the results are underestimated just after the upper edge of the rear slant surface. This means less turbulent mixing and thus a greater recirculation region. With the hybrid RANS-LES models, the TKE is overestimated and particu- 
larly at the end of the slanted surface. However, for the first X-positions on the slant, the results obtained with the IDDES model are in good agreement with the experimental data. In the wake of the model, as the hybrid RANS-LES approaches give a recirculation in better agreement with the experiments, the comparison of the TKE profiles matches the experimental data.

As for the $35^{\circ}$ slant angle, a comparison of the velocity components and the turbulent kinetic energy in the plane $\mathrm{Y}=180 \mathrm{~mm}$ is possible. Once again, the measurements are not available close to the wall. The $\mathrm{X}$ positions of the profiles are the same as those for the symmetry plane. The results for the velocity profiles obtained with the IDDES model are in agreement with the experimental data which indicates that the size of C-pillar vortices is well predicted. This is in agreement with Figure 18. With the other turbulence models, the agreement with the experimental data for the velocity components are poor. The turbulent kinetic energy, unlike the results in the symmetry plane, is not overestimated with the IDDES approach compared to the experiments.

As for the $35^{\circ}$ slant angle, the different parts of the pressure drag are indicated in Table 5. For the previous slant angle, $C_{S}$ and $C_{B}$ were about the same size. For the $25^{\circ}$ slant angle, it is not the case. The pressure drag for the rear slant is the greater part of the pressure drag. In the experiments, this drag represents $57.55 \%$ of the drag. This value is close to the value obtained with the IDDES model which is $58.25 \%$. Only the hybrid RANS-LES models predict a drag for the slant higher than the drag for the base. However, the ratio obtained with the DES approach underestimates the experiment value. As for the $35^{\circ}$ slant angle, the pressure drag for the front is underestimated by all turbulence models.

The force coefficients, the drag and the lift, are presented in Table 6 for all turbulence models. As for the $35^{\circ}$ slant angle, the experimental data of 515 Ahmed et al. [4] and Meile et al. [34] are also indicated. The results measured by Thacker et al [37], at the same Reynolds number used in this paper, are mentioned in this table. As the previous comparisons have shown that there are siginficant differences between all numerical simulations, it is not surprinsing 


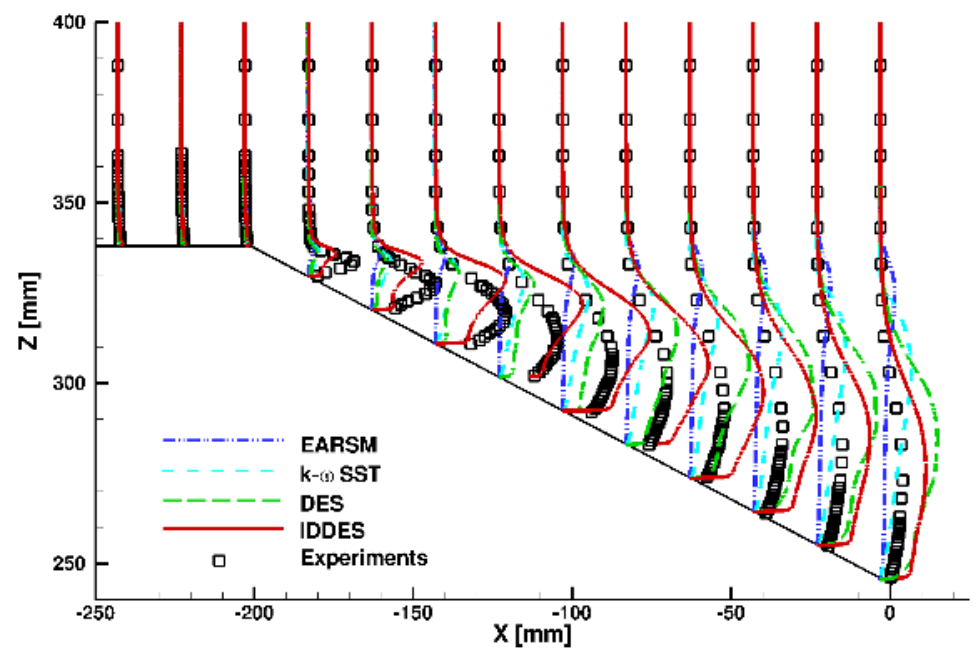

(a) On the slant

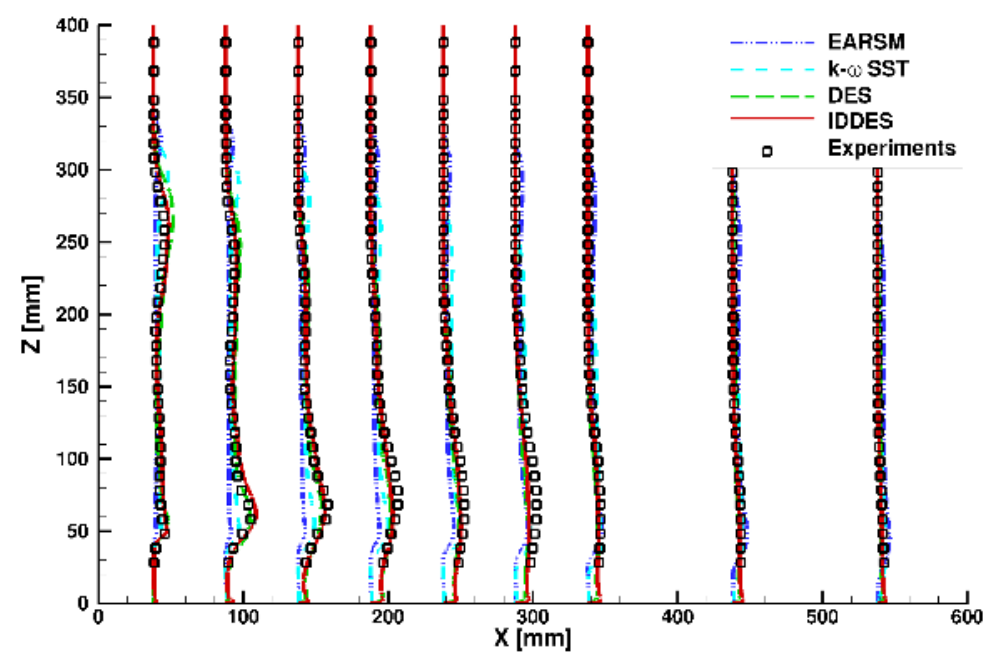

(b) In the wake

Figure 24: $25^{\circ}$ slant angle - Turbulent kinetic energy profiles in the symmetry plane.

that the drag coefficient varies depending of the turbulence model used. Even in

the experiments, the drag value is not the same. The drag coefficient obtained with the IDDES model is in good agreement with the drag measured by Thacker et al. [37]. The lift coefficient has the same order of magnitude with the hybrid 


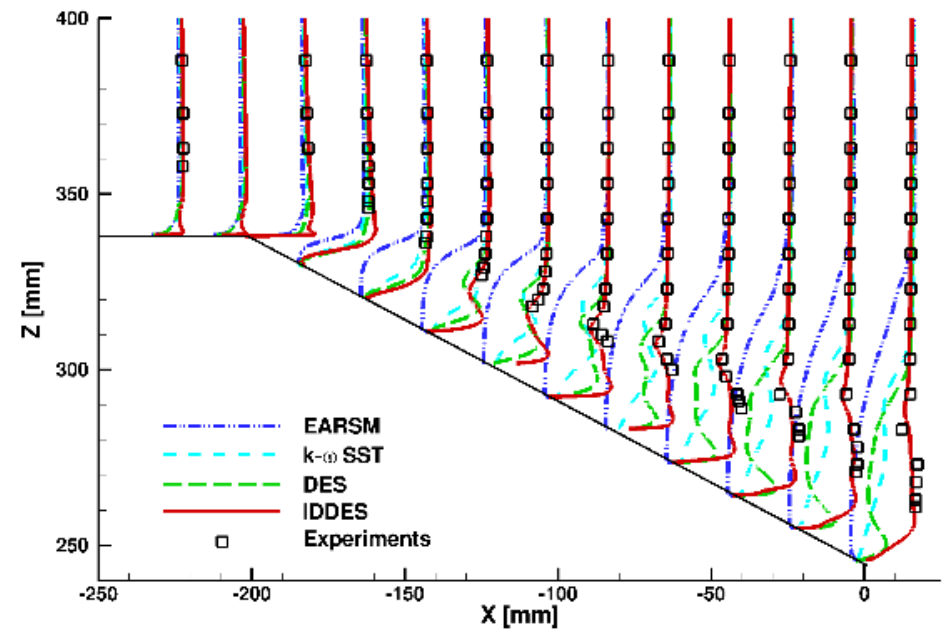

(a) Streamwise component

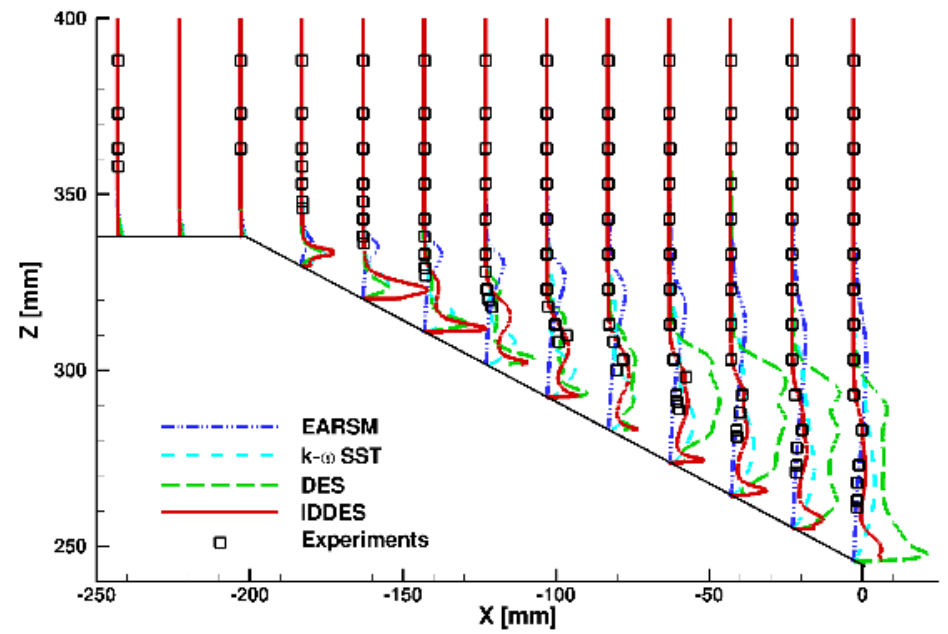

(b) Turbulence kinetic energy

Figure 25: $25^{\circ}$ slant angle - Velocity and turbulent kinetic energy profiles over the slanted surface in the plane $\mathrm{Y}=180 \mathrm{~mm}$.

RANS-LES models while with the RANS models this coefficient is lower, and particularly with the EARSM model. 
Table 5: $25^{\circ}$ slant angle - Pressure drag coefficient breakdown.

\begin{tabular}{lcccccc}
\hline Model & $C_{B}$ & $C_{B} / C_{D, P}[\%]$ & $C_{S}$ & $C_{S} / C_{D, P}[\%]$ & $C_{K}$ & $C_{K} / C_{D, P}[\%]$ \\
\hline$k-\omega$ SST & 0.1201 & 48.27 & 0.1195 & 48.02 & 0.0092 & 3.70 \\
EARSM & 0.1207 & 59.05 & 0.0726 & 35.49 & 0.0112 & 5.46 \\
DES & 0.1508 & 42.56 & 0.1916 & 54.08 & 0.0119 & 3.36 \\
IDDES & 0.1258 & 38.96 & 0.1880 & 58.25 & 0.0090 & 2.79 \\
Experiments [4] & 0.0860 & 35.10 & 0.1410 & 57.55 & 0.0180 & 7.35 \\
\hline
\end{tabular}

Table 6: $25^{\circ}$ slant angle - Drag and lift coefficients.

\begin{tabular}{cccccccc}
\hline & $k-\omega \mathrm{SST}$ & EARSM & DES & IDDES & Experiments [4] & Experiments [34] & Experiments [37] \\
\hline$C_{D}$ & 0.3218 & 0.2804 & 0.4371 & 0.3802 & 0.2850 & 0.2990 & 0.3840 \\
$C_{L}$ & 0.1724 & 0.0083 & 0.3747 & 0.3306 & n.a. & 0.3450 & 0.4220 \\
\hline
\end{tabular}

\section{Conclusions}

An investigation of RANS and hybrid RANS-LES turbulence models for the Ahmed body at $25^{\circ}$ and $35^{\circ}$ slant angle cases has been conducted. The RANS turbulence models used are $k-\omega$ SST and a EARSM. For the DES and IDDES hydrid RANS-LES approaches, these models are based on the $k-\omega$ model. This paper shows that the IDDES model offers an advantage over the other turbulence models used in terms of the force coefficients and general flow field at the two slant angles considered here.

For the $35^{\circ}$ slant angle, all simulations are in agreement with the experimental data. However, the IDDES model gives a better agreement, in particular at the shear layer of the separation and also for the ratio between the presure drag for the rear slant and the pressure drag for the base.

For the $25^{\circ}$ sant angle, the numerical results are highly dependent on the turbulence model used. The RANS approach fails to capture the separation bubble on the slant. The IDDES approach is the only one that predicts correctly the bubble on the slant as well as its size. Therefore, the velocity profiles and the turbulent kinetic energy are in agreement with the experimental data, even 
in the plane close the maximum width of the model.

So, this paper shows that the numerical simulations with IDDES model are able to reproduce the experiments.

With the aim of reducing vehicles fuel consumption, one way is to reduce aerodynamic drag using flow control techniques. Hence, the prediction of the wake is essential in order to compare the effects of the control. The IDDES approach can therefore used for such investigations.

\section{Acknowledgment}

This work was granted access to the HPC resources of CINES/IDRIS under the allocations 2015-2a0129 and 2016-2a0129 made by GENCI.

\section{References}

[1] P. R. Spalart, W. H. Jou, M. Strelets, S. R. Allmaras, Comments on the feasibility of LES for wings and on a hybrid RANS/LES approach, in: C. . Z. Liu (Ed.), 1st AFOSR International Conference on DNS/LES, Advances in DNS/LES, Greyden Press, 1997.

[2] A. Keating, J. Beedy, R. Shock, Lattice Boltzmann simulations of the DLRF4, DLR-F6 and variants, in: AIAA Aerospace Sciences Meeting and Exhibit, AIAA 2008-749, Reno, Nevada, 2008.

[3] D. C. Forbes, G. J. Page, M. A. Passmore, A. P. Gaylard, Computational study of wake structure and base pressure on a generic SUV model, in: International Vehicle Aerodynamics Conference, Loughborough University, 2014 .

[4] S. R. Ahmed, G. Ramm, G. Faltin, Some salient features of the timeaveraged ground vehicle wake, SAE World Congress, paper 840300 (1984).

[5] S. Jakirlić, R. Jester-Zrker, C. Tropea (Eds.), 9th joint ERCOFTAC/IAHR/QNET-CFD Workshop on Refined Turbulence Modelling, 2001. 
[6] R. Manceau, J. P. Bonnet (Eds.), 10th joint ERCOFTAC/IAHR/QNETCFD Workshop on Refined Turbulence Modelling, 2002.

[7] N. Ashton, A. West, S. Lardeau, A. Revell, Assessment of RANS and DES methods for realistic automotive models, Computers and Fluids 128 (2016) $1-15$.

[8] S. Kapadia, S. Roy, K. Wurtzler, Detached eddy simulation over a reference Ahmed car model, in: 41st Aerospace Sciences Meeting and Exhibit, AIAA Paper 2003-0857, Reno, NV, 2003.

[9] G. Martinant, R. Bourguet, Y. Hoarau, F. Dehaeze, B. Jorez, M. Braza, Numerical simulation of the flow in the wake of Ahmed body using detached eddy simulation and URANS modeling, in: S.-H. Peng, W. Haase (Eds.), Advances in Hybrid RANS-LES Modelling, Vol. NNFM 97, SpringerVerlag, 2008, pp. 125-131.

[10] T. Han, Computational analysis of three-dimensional turbulent flow around a bluff body in ground proximity, AIAA Journal 27 (9) (1989) 1213-1219.

[11] P. Gilliéron, F. Chometon, Modelling of stationary three-dimensional separated air flows around an Ahemd reference model, in: EASIM: Proceedings, Vol. 7 of Vortex Flows and Related Numerical Methods III, 1999, pp. 173182.

[12] E. Guilmineau, Computational study of flow around a simplified car body, Journal of Wind Engineering and Industrial Aerodynamics 96 (6-7) (2008) 1207-1217.

[13] N. Ashton, A. Revell, Key factors in the use of DDES for the flow around a simplified car, International Journal of Heat and Fluid Flow 54 (2015) $236-249$.

[14] E. Fares, Unsteady flow simulation of the Ahmed reference body using a lattice boltzmann approach, Computers and Fluids 35 (2006) 940-950. 
[15] C. Hinterberger, M. García-Villalba, W. Rodi, Large eddy simulation of flow around the Ahmed body, in: F. B. R. McCallen, J. Ross (Eds.), Lectures Notes in Applied and Computational Mechanics - The Aerodynamics of Heavy Vehicles: Trucks, Buses and Trains, Vol. 19, Springer-Verlag, 2004, pp. 77-87.

[16] S. Krajnović, L. Davidson, Flow around a simplified car - part 1: Large eddy simulation, Journal of Fluids Engineering 127 (2005) 907-918.

[17] M. Minguez, R. Pasquetti, E. Serre, High-order large eddy simulation of flow over the "Ahmed body" car model, Physics of Fluids 20.

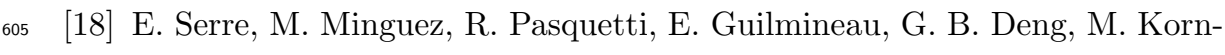
haas, M. Schäfer, J. Frölich, C. Hinterberger, W. Rodi, On simulating the turbulent flow around the Ahmed body: A French-German collaborative evaluation of LES and DES, Computers \& Fluids 78 (2013) 10-23.

[19] E. Guilmineau, G. B. Deng, J. Wackers, Numerical simulation with a DES approach for automotive flows, Journal of Fluids and Structures 27 (2011) $807-816$.

[20] M. L. Shur, P. R. Spalart, M. K. Strelets, A. K. Travin, A hybrid RANSLES approach with delayed-DES and wall-modelled LES capablities, International Journal of Heat and Fluid Flow 29 (2008) 1638-1649.

${ }_{615}^{621]}$ I. Kohri, Y. Kobayashi, A. Kasai, T. Nasu, Experimental analysis on the transition mechanism of the wake structure of the Ahmed body, SAE International Journal of Passenger Cars - Mechanical Systems 9 (2) (2016) 612-624, doi:10.4271/2016-01-1591.

[22] H. Lienhart, S. Becker, Flow and turbulence in the wake of a simplified car model, SAE World Congress, paper 2003-01-0656 (2003).

[23] R. J. A. Howard, M. Pourquie, Large eddy simulation on the Ahmed reference model, Journal of Turbulence 3 (1). 
[24] R. Duvigneau, M. Visonneau, G. B. Deng, On the role played by turbulence closures in hull ship optimization at model and full scale, Journal of Marine Science and Technology 8 (2003) 11-25.

[25] G. B. Deng, M. Visonneau, Comparison of explicit algebraic stress models and second-order turbulence closures for steady flow around ships, in: 7th Symposium on Numerical Ship Hydrodynamics, Nantes, France, 1999, pp. 4.4-1-15.

[26] M. S. Gritskevich, A. V. Garbaruk, J. Schütze, F. R. Menter, Development of DDES and IDDES formulations for the $k-\omega$ shear stress transport model, Flow, Turbulence and Combustion 88 (2012) 431-449.

[27] S. Krajnović, S. Sarmast, LES of the flow around a generic wheel in a wheelhouse, in: 3rd Joint US-European Fluids Engineering Summer Meeting, Montreal, Canada, 2010, FEDSM-ICNMM2010-30687.

[28] C. M. Rhie, W. L. Chow, A numerical study of the turbulent flow past an isolated aerofoil with trailing edge separation, AIAA Journal 17 (11) (1983) $1525-1532$.

[29] R. Issa, Solution of the implicitly discretized fluid flow equations by operator-splitting, Journal of Computational Physics 62 (1985) 40-65.

[30] P. Queutey, M. Visonneau, An interface capturing method for free-surface hydrodynamic flows, Computers and Fluids 36 (2007) 1481-1510.

[31] F. R. Menter, Two-equation eddy viscosity turbulence models for engineering applications, AIAA Journal 32 (1994) 1299-1310.

${ }_{645}[32]$ M. Strelets, Detached eddy simulation of massively separated flows, AIAA Paper 2001-0879 (2001).

[33] J. Keogh, T. Barber, S. Diasinos, G. Doig, The aerodynamic effects on a cornering Ahmed body, Journal of Wind Engineering and Industrial Aerodynamics 154 (2016) 34-46. 
[34] W. Meile, G. Brenn, A. Reppenhagen, B. Lechner, A. Fuchs, Experiments and numerical simulations on the aerodynamics of the Ahmed body, CFD Letters 3 (1) (2011) 32-39.

[35] A. Spohn, P. Gilliéron, Flow separations generated by a simplified geometry of an automotive vehicle, in: IUTAM Symposium on Unsteady Separated

655 Flows, Toulouse, France, 2002.

[36] A. Thacker, Contribution expérimentale à l'analyse stationnaire et instationnaire de l'écoulement à l'arrière d'un corps de faible allongement, Ph.D. thesis, Université d'Orléans (2010).

[37] A. Thacker, S. Aubrun, A. Leroy, P. Devinant, Effects of suppressing the 3D separation on the rear slant on the flow structures around the Ahmed body, Journal of Wind Engineering and Industrial Aerodynamics 107-108 (2012) 237-243. 